\title{
A Review of X-ray Explosives Detection Techniques for Checked Baggage
}

\author{
K. Wells ${ }^{1,3}$ and D.A. Bradley ${ }^{2,3}$ \\ ${ }^{1}$ Centre for Vision Speech and Signal Processing \\ ${ }^{2}$ Department of Physics \\ Faculty of Engineering and Physical Sciences, University of Surrey \\ Guildford, Surrey GU2 7XH United Kingdom \\ and \\ ${ }^{3}$ Dept of Radiological Sciences, King Saud University, Riyadh, \\ Kingdom of Saudi Arabia
}




\begin{abstract}
In recent times, the security focus for civil aviation has shifted from hijacking in the 1980s, towards deliberate sabotage. X-ray imaging provides a major tool in checked baggage inspection, with various sensitive techniques being brought to bear in determining the form, and density of items within luggage as well as other material dependent parameters. This review first examines the various challenges to X-ray technology in securing a safe system of passenger transportation. An overview is then presented of the various conventional and less conventional approaches that are available to the airline industry, leading to developments in state-of-the-art imaging technology supported by enhanced machine and observer-based decision making principles.
\end{abstract}




\section{Introduction}

\subsection{Security Perspectives}

In US skies, commercial aviation in 2009 was said to involve upwards of 28000 flights daily, with around 5000 actually flying at any one time (Seidenstat \& Splane, 2009). In the same year, a Boeing Company estimate of the worldwide number of commercial flights, suggested this to be of the order of 49,000 flights daily. The demands for security in movement of the accompanying checked baggage are clearly enormous. As an indicator, according to Oster and Strong (2008), about $\$ 4.7$ billion of the US Transport Security Administration (TSA) annual $\$ 6.7$ billion budget at the time was spent on airport-related security (excluding cargo security).

Since its inception, there has been a need for the screening of passengers and their baggage for three main purposes (ECORYS, 2009): (i) the illegal movement of goods or prohibited items, according to the local legislative requirements, (ii) fraud and revenue avoidance; and in ever-increasing importance (ii) terrorist threat, prompted by the first recorded hijacking of a PanAm mail plane by Peruvian activists in 1930.

However in more recent times, the security focus for civil aviation has shifted: from hijacking in the 1980s, following the incident with TWA Flight 847 in the Middle East, towards deliberate sabotage, and the use of IEDs in the 1990s (Fobes \& Klock, 1995). With annual aviation activity growing internationally at a rate of some 3-5\% (Markarian et al, 2011), terrorist attack is an on-going primary focus of aviation security activity. However following the devastating 9/11 attacks and subsequent attempted civil air attacks such as the shoebomber (Schweitzer, 2002; Seidenstat \& Splane, 2009), hijacking/air suicide per-se has become that much more unlikely owing to improved aviation security and intelligence. Thus, the focus of security activity in the civil aviation sector has now shifted to the identification of illicitly-transported explosives as the main terrorist threat wherein such commercial flights are significantly threatened by relatively limited quantities of concealed explosive. Hence, the success (or otherwise) of civil aviation security depends critically on efficient detection of explosives, frequently manifest as HME (Home-made explosive) in hand or checked luggage and freight, the composition and appearance of which may be easily confused with benign everyday items of luggage.

Essentially there are four major approaches available for the inspection of screened baggage (Butler \& Poole, 2002, Singh \& Singh, 2003), including: manual hand search (sometimes 
referred to as 'pat-down'); sniffer dogs; Trace Explosives Detection (TED); Automated X-ray inspection including certified explosives detection systems.

\subsection{New Explosives Challenges}

Manual search is slow and laborious, leading to only a few tens of bags per hour inspection rates. Dogs are capable of several hundred bags per hour, but both of these methods are relatively slow. While sniffer dog performance has been reported as having high detection rates and low false alarms (ECORYS, 2009 and references therein), the dogs are only fit for duty for an hour or so before needing to be rested. Thus manual inspection and sniffer dogs are often used as second-level inspection methods, once an initial trigger has been produced (Butler \& Poole, 2002). Trace Detection is also a slow process, achieving inspection rates similar to manual search, and in the current climate represents a throughput that is unacceptable in most busy airports. Automated X-ray inspection systems using computed tomography methods have been licensed in Europe for some time, but are now only starting to be recognised and rolled out more widely across the US.

Conventional X-ray imaging is used for bulk explosive detection and is based both on the form and density of the luggage contents: those items whose densities are similar to those of known explosives are labelled as potential threats. As we will learn later, while this can represent a considerable challenge to the more conventional $\mathrm{x}$-ray techniques, there are a number of less conventional approaches that increase sensitivity to a given media.

The 2006 transatlantic aircraft plot (Seidenstat \& Splane, 2009) firmly placed the threat from liquid HME centre-stage and heralded in a new era of liquid carry-on luggage prohibition and subsequent tight limited carry-on controls regarding liquids in personal hand-held luggage. Only now, some five years later is due consideration starting to be given to relax these measures (Markarian et al, 2011). Such draconian regulation was implemented for want of an efficient method for detecting HMEs and liquid explosives, although such actions have also been seen to be little more than 'Aviation Theatre' (Segan, 2011). A decision has subsequently been made by the EU to lift this ban in Europe, to be eased in a phased approach starting from 2011 (a date which, at the time of writing, has not been met), with 'a clear and final deadline' in April 2013. Clearly this has had to be accompanied by development of mass-screening technology to detect explosives in fluids to maintain adequate security whist reducing the restrictive security burdens on the air passenger community. 
In regard to mass-screening technology for luggage (carry-on and checked), various technological solutions began to be commercially available several decades ago, several of these being practically adopted in one form or another. These systems are based on many physical principles: trace analysis, Raman spectroscopy, dual- or multi-energy X-rays in transmission, X-ray diffraction, etc. For equipment to really fit security needs, it should have a high probability of detection and a very low false alarm rate; in other words it requires high sensitivity (i.e. the ability to correctly identify a threat when a threat is present) and high specificity (the ability to label benign objects as nil-threats). Given the changes in the nature of the civil aviation security threat, and the new techniques and technologies which have grown-up to address these threats, this article seeks to address in particular the high throughout technologies: namely those that harness state-of-the-art in x-ray interrogation methods. Competitor neutron interrogation methods are at the current time far less mature in technological development and as such are deemed beyond the scope of this article.

With respect to throughput and the advancement of automation and the bringing to bear of novel physics, we confine the article to methods employed to checked (or Hold) baggage only. We describe the underlying physical principles employed in the detection process, and in so far as is possible (without compromising the useful deployment of these), describe their ultimate performance for detecting liquid explosives and HMEs, in addition to conventional plastic explosives. The metric we adopt for comparing ultimate performance is the number of independent physical features that the method yields, on the assumption that the greater the number of features a method delivers, the higher its ultimate performance (see section 3.2).

Specifically this paper considers the following aspects in implementation of state of the art $\mathrm{x}$ ray methods for checked baggage: the large variety of HMEs and liquid explosives with precursors; the realities of practical operation (airport, mandatory minimum throughput, large variety of luggage in terms of content, etc); the existing and foreseeable regulatory framework (e.g. EC185) in the EU and US. We consider current X-ray screening technologies including: single-view with/without energy resolution; multi-view with/without dual energy, CT with/without energy resolution; $\mathrm{x}$-ray diffraction imaging, and cast a prospective eye towards forthcoming technologies, as in for instance room temperature energy resolving $\mathrm{x}$-ray detectors. It is important to stress that the paper examines ultimate performance of the technology, exclusive of cost impact, data for the latter being largely inaccessible.

It should of course be realised at the outset of this article that there are details which are clearly inappropriate for wider dissemination in respect of security of such sensitive knowledge. As a matter of exclusion, such issues will include any statements that purport to represent quantified minimum levels of detection for particular technologies. Security of 
information apart, the competitive nature of the various enterprises means that in any case that such data are not typically a matter of public declaration, it being up to those involved to demonstrate performance to the end-user. Nonetheless, the general methodologies involved in evaluating detection limits are well understood, with widespread discussion in terms of medical and industrial applications. As such, the typical operational constraints under which airports operate and the generalities of decision levels will be included herein, driven by prevailing threats.

\section{Operational Issues}

\subsection{Top-level system description of screening process}

There are well known limits on the size of carry-on baggage, often quoted in terms of linear inches (the sum of the height, width and length), usually set at around 45 linear inches. However, it is less well-known that there are also physical limits placed on checked baggage. Whilst some small variations exist between domestic and international flights, the standard limits are 62 linear inches and an upper weight limit of $50 \mathrm{lbs}$ (around $20 \mathrm{~kg}$ ), depending on the particular carrier and the type of ticket issued. Baggage outside of these limits may be refused passage or be liable for excess baggage penalties.

Construction materials used in a typical checked bag may derived from plastic, fabric, leather man-made or natural fabrics, metal-framed or a mixture of these. However, for scanning personnel, it is the contents of the bag that are of primary importance, as, when combined with the material and construction of holdalls and baggage, produces a background scene in which potential targets may be present. In this regard it is practically-speaking impossible to make assumptions about the contents of carry-on baggage. Aside from the various prohibited items such as weapons (guns), ammunition, various foodstuffs, of sensitive material (e.g. pornography) that various border agencies enforce, one cannot make any assumptions about the contents of carry-on baggage. This has been exploited by terrorist groups, such that explosives can often appear, from X-ray inspection, to appear to look like every day, benign items. For example, dynamite can have the appearance of a bar of marzipan. 
Table 1 Adapted from Geo Robson, (2011) describes the ECAC screening regulations. Levels 1-3 are of primary interest in this paper.

\begin{tabular}{|c|c|}
\hline Level & Action \\
\hline 1 & Automated evaluation of the X-ray image by the X-ray Machine. \\
\hline 2 & $\begin{array}{l}\text { Operator analysis of the Level } 1 \text { image at a workstation(s), carried out whilst } \\
\text { the bag continues in transit. }\end{array}$ \\
\hline 3 & $\begin{array}{l}\text { A more in-depth analysis of the original Level } 1 \text { image at a separate } \\
\text { workstation(s) or subjecting the bag to a separate X-ray process using a } \\
\text { different X-ray technology, for example Computer Tomography (CT Scanner). }\end{array}$ \\
\hline 4 & Re-uniting the passenger and bag and carrying out a manual search. \\
\hline 5 & $\begin{array}{l}\text { In the event that the passenger cannot be found, then the bag is considered } \\
\text { a bomb threat and dealt with accordingly. }\end{array}$ \\
\hline
\end{tabular}

The screening of checked baggage has been a routine procedure in for instance the UK and in Israel for many years due to on-going terrorist threats in both of these countries since the 1970s. However the 9/11 attacks prompted the US government to dramatically revise its screening procedures: with the inception of the Transportation Security Administration (TSA) (Oster \& Strong, 2008), all checked luggage is screened for explosives. In the initial phase in the immediate aftermath of the $9 / 11$ attacks, the US Government planned to invest $\$ 12$ billion (Butler \& Poole, 2002) in rapidly deploying 100\% screening programmes for all checked baggage involving two major technologies: at the time, the US had only one licensed automatic explosive detection system (InVision Technologies CTX 5000), and it became apparent that it would be impossible to meet the $100 \%$ checked baggage task by the prescribed deadline. Thus an interim solution was proposed that combined Explosive Detection Systems (EDS) and ETD (Explosives Trace Detection; note that this involves taking a swab from an item and placing it in a spectrometer which will analyse the vapours and match against known templates.). Both of these approaches, were slow with the CTX5000 only capable of handling around 150-200 bags per hour and having a false positive rate of around $30 \%$. There were also reports of reliability issues. This led to significant delays for air passengers (Butler \& Poole, 2002; Bretz, 2002), requiring an extra hour for the checkin process prior to departure for hand and checked hold baggage. Drawing on lessons learnt from the European model, the US approach is now starting to mirror the selective risk-based approaches to screening adopted in Europe, although there has been criticism that progress towards this approach has been slow (Segan, 2011). Since that time the international baggage screening community has adopted a Five-Level Screening Process, summarised in Table 1. Moreover the latest generation of CT-based scanners now have throughputs of several hundred bags per hour with enhanced levels of performance. 
Table 2. Baggage scanning performance of a selection of market leader EDS products utilising CT technology. Throughput rates are as claimed by manufacturer. Where two figures are quoted, the first is for in-line configurations, while the second is for stand alone configurations

\begin{tabular}{|l|l|l|}
\hline Manufacturer & Product designator & $\begin{array}{l}\text { Throughput rate } \\
\text { [bags per hour] }\end{array}$ \\
\hline Rapiscan & RTT (Real time tomography) & $\begin{array}{l}800-1800 \\
{[\text { dependant on belt speed] }]}\end{array}$ \\
\hline $\begin{array}{l}\text { Morpho } \\
\text { Detection Inc. }\end{array}$ & 5800 & 500 \\
\hline $\begin{array}{l}\text { Analogic } / \\
\text { Communications }\end{array}$ & eXaminer SX & 1000 \\
\hline $\begin{array}{l}\text { Science } \\
\text { Inplications } \\
\text { Corporation } \\
\text { (SAIC) }\end{array}$ & eXaminer XLB & $360 / 300$ \\
\hline $\begin{array}{l}\text { Siemens } \\
\text { CT-80DR }\end{array}$ & $\begin{array}{l}550 *, 730 / 440 \\
1200[\text { continuous flow }]\end{array}$ \\
\hline
\end{tabular}

\subsection{Summary of Legislative Framework in EU and US}

The current network of direct and in-direct flights across the globe has grown up over 90 or so years of transcontinental air travel. The parallel development of security screening methods deployed to ensure safe transit of passengers and cargo has grown up hand-in-hand with the expansion of this activity, and in particular since the signing of 'Open Skies' agreements by the US and many partner nations ${ }^{1}$. Partner nations (or more precisely their nominated air travel administrations) have developed partner agreements to ensure that passengers/baggage entering the air travel arena are safely screened on entry and exit. Such

\footnotetext{
${ }^{1}$ Open Skies agreements essentially relax laws governing air travel for passengers, cargo and mixed flights between the two partner nations. This follows a principle of minimal Government intervention, and thus stimulation and growth of air travel between Open Skies partners.
} 
partner arrangements have been developed across most of the Western world. However, there remain parts of the globe where direct flights to major Western hubs are prohibited, particularly since the 9/11 attacks, until International Civil Aviation Organization (ICAO) security standards and regulations and FAA Category I certification (Sample et al, 2004) is secured.

ICAO Annex 17 of April 2003 'Security - Safeguarding International Aviation Against Unlawful Interference' sets out the standards and methods to be used Category I Certification. These can be summarised as follows (Sample et al, 2004):

Poole (2008) has described the current legislative framework for airline baggage security. The nature of high jacking activity in the 1960s and 1970s was quite different in the US and Europe, with the former being affected by political activists, whilst the latter was dominated by individuals/groups seeking financial reward. This led to the development of quite different approaches to the screening of passengers and their baggage. Nonetheless certain areas of common interest arose to provide an internationals set of rights for those passengers from member states of the International Civil Aviation Organization (ICAO), adopting what is now termed 'Annex 17' of the Convention on International Civil Aviation, commonly known as the Chicago Convention.

Doherty (2009) has suggested that 'sampling and detection methods are needed that are able to screen at a fast rate (nominally $<5$ seconds) while maintaining a low false alarm rate (false positives) and a high enough rate of detection (true positives) to deter terrorist use of HMEs. Ideally, the sampling and detection methods should be useable in various venues with an emphasis on transportation (air) checkpoints (most critical due to the small amount of explosive needed to create catastrophic damage).

\subsection{Prohibited items for carry-on or checked luggage within legal framework}

Although internationally there might be expected to be some minor variation in such listed items, perhaps the best known listings are those of the United States Transport Security Administration (TSA), detailed and regularly updated in respect of allowed and prohibited items (http://www.tsa.gov/travelers/airtravel/prohibited/permitted-prohibited-items.shtm). Present levels of control come about as a result of enactments of H.R. 3150, the Secure Transportation for America Act of 2001. Under H.R. 3150, airline security screening is federalized under a new Transportation Security Administration (TSA) within the U.S. Department of Transportation. The TSA is required to: 1) enact stricter standards for the 
screening of airline passengers and baggage; 2) conduct extensive background checks on all airport security personnel; 3) provide the training for and testing of all airport security personnel; and 4) provide uniformed federal officials to supervise the screening of all passengers and baggage at airports.

At EU airports, civil aviation security is governed by Regulations (EC) Nos. 300/2008 and, 185/2010, which came into effect on 29 April 2010. The Annex to Regulation (EC) No. 185/2010 contains a list of items that are prohibited from being carried in the hold of an aircraft. This list of prohibited items is available to the public and includes explosives and incendiary substances and devices explosives and incendiary substances and devices capable of being used to cause serious injury or to pose a threat to the safety of aircraft, Among the items listed as prohibited from being carried in the hold of an aircraft is ammunition. However, according to point 5.4.2 of the Annex to Regulation (EC) $185 / 2010$, exemptions may be granted on condition that the appropriate authority has national rules permitting the carriage of the article and, that applicable safety rules are complied with.

A key issue highlighted by Singh \& Singh (2003) is that baggage contents fall into two major categories: solid (or liquid) and textile objects (ie clothing, cloth-based objects). In terms of easy identification of potential hazards against benign objects, either by machine or operator, this produces a number of confusing issues: the textile may appear (at least in 2D projection) to wrap itself around a solid object, wherein the intrinsic 'texture' of the textile confuses attempts to localise the boundary of the solid object because of overlapping pixel grey levels.

\section{Decision Principles}

\subsection{Decision Classification}

Having described the operational issues associated with running an efficient baggage screening service, we now describe the decision-making process in baggage screening. In order to characterise the decision-making process in any machine or human-based screening operation, the standard approach used is to draw on signal detection theory, first developed by the US Army during WWII to measure the performance of radar operators (Green \& Swets, 1966). Apart from the broad identification of hit/miss with regards to the detection of a prohibited item, we may classify the outcomes found in the decision making proceeds into four main categories, as shown by the Confusion matrix shown in Figure 1. 


\section{Actual State}

Target Present

No target

\begin{tabular}{|c|c|c|c|}
\hline Classified & Yes & True Positive (TP) & False Positive (FP) \\
\hline $\begin{array}{l}\text { Decision } \\
\text { Outcome }\end{array}$ & No & False Negative (FN) & True Negative (TN) \\
\hline
\end{tabular}

Figure 1. Confusion Matrix

We now assume that the process of detection is characterised by some tell-tale signal or feature which the screener can sense. This might be the mental matching of some template of a prohibited item, such as a hand gun, or it could be some measure of how well a chemical spectrum from a sample matches that of a known prohibited item. A binary hit/miss decision is then determined by setting a threshold response with the Hit/Miss classification decision made either side of the threshold. If we assume the signal produces a normal distribution of responses that the screener or screening instrument detects, then the presence/absence of a particular threat or prohibited item might be expected to produce two normal, or Gaussian, distributions - see Figure 2. The components of these decisions can then be classified as shown in the Confusion Matrix in Fig. 1. The two misclassification terms False Positive and False Negative are critical classes to minimise in any classification or decision making task. The False Positives may be considered as 'False Alarms', and in statistical terms are often referred to as a Type I error. Similarly, a False Negative, which may also be considered a 'Miss' is statistically referred to as a Type II error.

\begin{tabular}{|c|c|}
\hline Quantity & Definition \\
\hline Detection Probability, True Positive Rate (TPR) or Sensitivity & $\frac{T P}{T P+F N}$ \\
\hline Specificity/ /True Negative Rate (TNR) & $\frac{T N}{F P+T N}$ \\
\hline False Alarm Rate or False Positive Rate $\quad(=1-$ Specificity) & $\frac{F P}{F P+T N}$ \\
\hline Accuracy & $\frac{T P+T N}{T P+F P+F P+F N}$ \\
\hline
\end{tabular}

Table 3. A selection of common quantities derived from the Confusion Matrix 
Using the above, a variety of different performance metrics have been established, the most well-known of which are summarised in Table 3. One of the most common of these is the Detection Probability (or Sensitivity). This represents the ability of a test to correctly identify target presence, given that a target is actually present, and is also sometimes referred to as the Hit Probability, $\mathrm{P}_{\mathrm{d}}$. A secod key performance metric is the False Alarm Rate (= 1Specificity), which represents the rate at which items are incorrectly labelled as threast when they are in fact benign. Several comments are worth making before proceeding further. First, that in computer-based training and testing, the incidence of true Hits and Misses is often set at 50\%. This would produce two distributions similar to those seen in Fig. 2, which can usually be assumed to be well-described as Gaussian distributions (Green \& Swets, 1974). However, in reality, the presence of a target or threat is usually a rare event, and therefore, one needs to be aware that the 'Signal' distributions (TP+FN) in Fig 2 would, in actuality, most likely have a much lower area under the curve, compared to the (FN+TN) curve.

Note that the threshold in Fig 2 has been placed at what is sometimes referred to as the optimal value. Optimal, in this sense, means that misclassification of items (False Positive and False Negatives) is minimised. However, in many screening applications this would be a poor choice of decision threshold: it may well be considered better to shift the threshold such that the number of False Alarms (FPR) is increased, in order to minimise the probability of a catastrophic event occurring due to false negative classification.

\subsection{Receiver Operator Characteristic (ROC) Analysis}

Now that these quantities have been established, we can consider how the common ROC (Receiver Operator Curve) is constructed. This is constructed from plotting the False Alarm Rate against the Probability of Detection or True Positive Rate across all decision thresholds. This gives rise to a characteristic curve, as shown in Fig. 3. The most simple performance measure determined from the ROC curve is the Area under the Curve. The ideal AUC $=1$ whereas repeated random guessing can be expected to produce an ROC curve representing a line of unity $(\mathrm{y}=\mathrm{x})$, with an AUC approaching 0.5 (within the statistical limits of the number of samples available). In practice useful detection systems exhibit areas between 0.5 and 1 .

A well-known Figure of Merit (FoM) is $d^{\prime}$ (d-prime). In referring to Fig $1, d^{\prime}$ is a measure of how well the two distributions are separated, in unit of standard deviation or Z-values, by resorting to use of standard statistical tables. It is calculated as $\mathrm{z}(\mathrm{H})-\mathrm{z}(\mathrm{FA})$ where $\mathrm{H}$ denotes the Hit rate (TP+FP), FA, the False Alarm Rate, and $\mathrm{z}$ is the transformation into units of standard deviation. Thus, when separation is large, then sensitivity is increased and the false alarm rate is reduced. Conversely, when there is little separation, the large overlap in the 
tails of the distributions will produce poor discrimination between the different decision outcomes. When this is calculated, then $d^{\prime}$ can be used to produce the resulting ROC curve and AUC.

$A^{\prime}$ (A-prime) is sometimes used to estimate the ROC using a single data point (Schwaninger, 2005 and references therein) and is often referred to as a non-parametric measure. In this case the AUC represents the average of the two ROC curves that minimise and maximise the detection rate.

Fobes et al (1996) considered the ability of baggage screening to detect IEDs at major US airports, in the pre-9/11 period wherein screening was handled by private companies. The problems of this situation are described elsewhere in this article, and Fobes et al highlight the variations in screening ability at different airports with $d^{\prime}$, representing the sensitivity of the screener, varying between 1.68 (Honolulu) and 1.00 (Los Angeles). The authors also use the probability of detection and the false alarm rates for assessment. It may be worth noting that unlike many contemporary studies, Fobes et al (1996) only used 25 IED threats distributed among an image set of 521, such that the true positive rate was very low. This may represent a more challenging situation to the screener (albeit perhaps more realistic) compared to the 50 $\%$ target incidence used in more contemporary work, wherein in the latter case the screener can recognise and rapidly adapt to an expected rate of positive identification. The authors warn that relying on the probability for detection (and the associated false alarm rate) alone can give an overly optimistic measure of screening performance, as it varies with the observer's decision strategy at that moment.

When the Gaussian assumption is valid (Green \& Svets, 1974), then a simple two parameter index can be used as a figure of merit, known as $D(\Delta m, s)$ (Guignard \& Salehi, 1983). In this case $\Delta m$ represents the distance between the means of the two Gaussian distributions, and $s$ is the ratio of their standard deviations. It is worth noting that it may be possible to produce situations where the long-established Gaussian assumption is in fact no longer valid (Guignard \& Salehi, 1983). It is also worth noting that a useless detection system with an AUC $<0.5$ can be easily enhanced by inverting its ROC curve. However, the singularly best way to improve ROC performance is to use more than one feature. This process is obviously used routionely by operators as shape, density and other pertinent information is fused together in the operators perception of a potential threat. In contrast, machine-based classification used to aid screening operators can also be used with a combination of features. For example, X-ray methods conventionally only use relative $\mathrm{x}$-ray transmission along a single axis. However, using two X-ray energy spectra, the information can be fused to produce a map of effective $\mathrm{Z}$ and mass density (eg Yang et al, 2007). This can be used to 
highlight potential threat areas/volumes within the image data, such as the presence of organic material. However, there is also now scanning technology becoming commercially available which can also explicitly use multiple features (Harding, 2004); X-ray transmission can be combined with scatter imaging, as described later in this paper. In this case these features can be plotted in an $\mathrm{N}$-dimensional feature space (where $\mathrm{N}$ is the number of measured features), and then statistical classification schemes can be used to form decision thresholds or hyperplanes between the feature cluster of threat or target region and that of benign objects as schematically illustrated in Figure 4. Details of the approaches are beyond the remit of this paper, save to mention some of the most used methods such as fuzzy C-means, linear discriminant analysis (LDA), or support vector machines (SVMs), the latter being capable of producing decision boundaries of arbitrary dimensionality and complexity. See Bishop, (2006) or similar texts for further details.

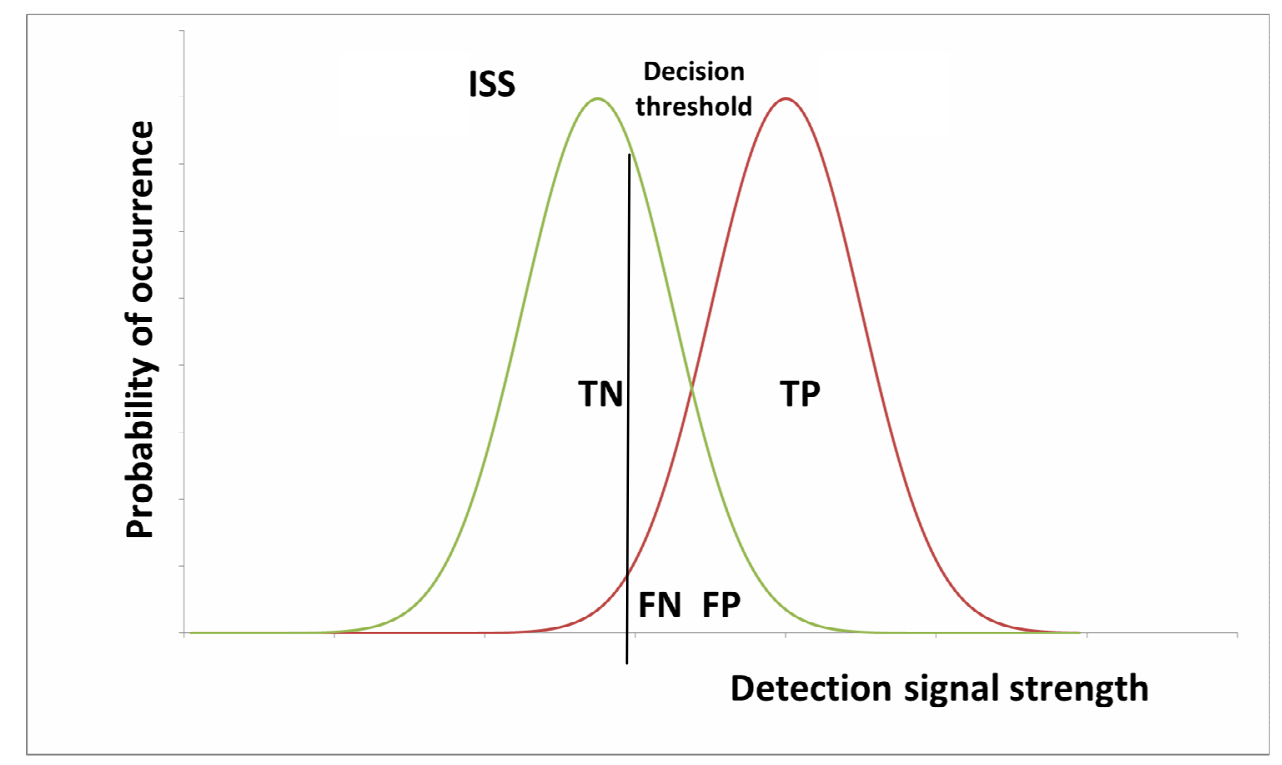

Fig 2 Associated decision distributions with respect to detection signal strength

However, it is worth adding that caution should always be used in relying on stand-alone FoMs: any such metric, by its nature is a summary of the true behaviour of the classification system and as such cannot express the subtle trade-offs between sensitivity (TPF) and specificity (1-FPR) that produces the headline FoM. 


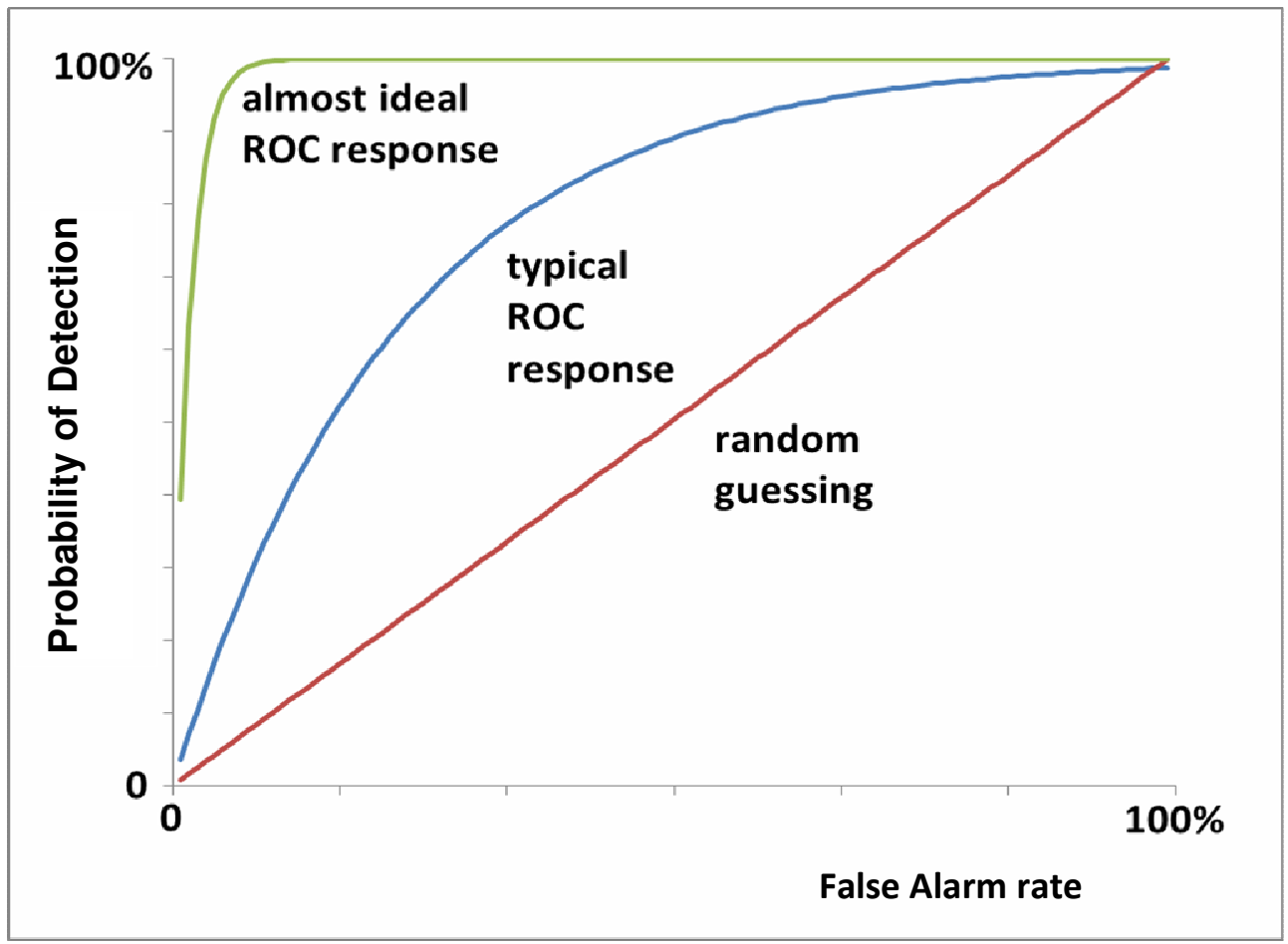

Fig 3 A selection of ROC curves demonstrating different levels of performance

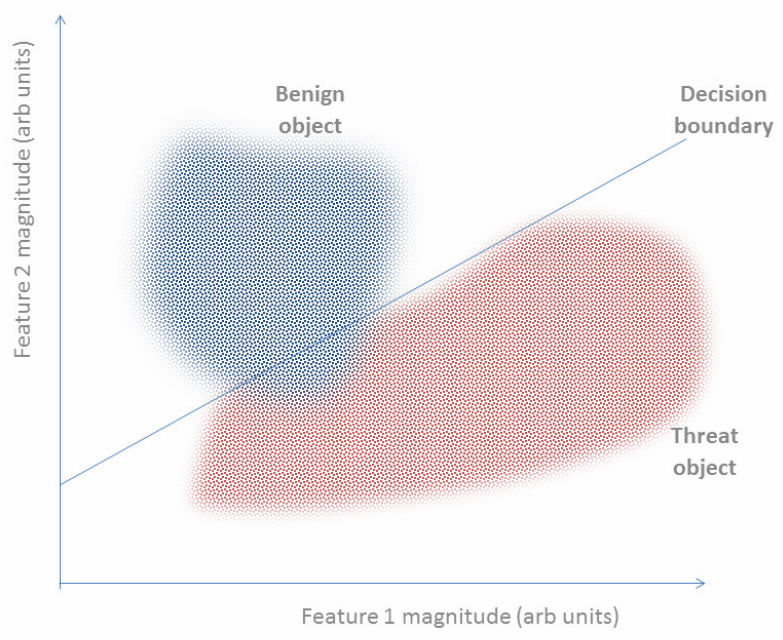

Figure 4 Schematic representation of an idealised 2D feature space, and the observed responses of two independent features for a variety of different threat and benign objects. The overlapping nature of the two distributions projected along each feature axis has the potential to cause confusion and poor performance when a single feature test is employed. However, a 2D decision boundary as shown allows good separation between threat and benign objects, providing better discrimination than applying a single threshold to either feature alone. This approach can also, in principle, be extended to higher dimensional feature spaces. 


\subsection{Operational Considerations for Baggage Inspection}

\subsubsection{Pre/Post 9/11 Screening}

Up to 2001, baggage inspection philosophies in the US and Western Europe diverged quite dramatically - policies had developed as a result of the very different types of threat that had grown up as described in section 2, with only $5 \%$ of US checked baggage actually screened. Prior to $9 / 11$ checked baggage was undertaken by private security companies employing $16.2 \mathrm{k}$ baggage screeners, wherein there was little (12 hours) time spent on training before starting official screening work. Moreover these companies generally paid poor wages (quoted in one report as being less than working at a fast food outlet (Segan, 2011), resulting in low morale and high staff turnover. Post-09/11, changes to the TSA controlled security screening process meant that the number of screeners was expanded to 56k screeners (but then subsequently reduced to $46 \mathrm{k}$ ), and that screening personnel were provided with typically over 100 hours of training (Blalock et al, 2007). Given that, on average, a screener has typically between 3-6 seconds to make a decision on a single x-ray baggage image (Al-Fundi et al, 2009), the need for extensive training is self-evident.

Post 9/11 one of the major changes introduced by the newly established TSA was that $100 \%$ of all hold baggage would be scanned for threat items, in particular, for IEDs (Bretz, 2002). At the time, theavailable semi-automated screening technology was only capable of screening 150 - 200 bags per hour with a relatively high FPR of 30\% (Blalock et al, 2007), resulting in severe delays for passengers (Bretz, 2002) The result of these security investments in screening also inevitably produced delays in international and nation air travel. Blalock (2007) found that this could be estimated to reduce passenger volumes by $5 \%$ (and a subsequent higher attributable civilian road death rate due to transport choices ), providing strong motivation for enhanced throughput technologies as well as efficient and effective screening methods.

Several different tests may be used for screeners including the Object Recognition Test and the Prohibited Item Test (PIT). The PIT is sued to establish whether a screener understands what items are prohibited and what items are accepted. It consists of a set of images of knives, sharp objects guns and explosives, and is designed to assess the knowledge component of a screener's skill set. By contrast the ORT is designed to assess the detection abilities of a screener to bag complexity. These factors have been broadly associated with three main image-based factors: complexity, superposition, and viewpoint of the target 


\subsubsection{Observer Training}

'the best technology is only as valuable as the humans that operate it', supporting the case for high levels of initial and on-going training of baggage screening operatives. Schwaninger (2004)

As part of the on-going development of baggage screening training processes, several types of tests and test objects have been developed in the US and Europe, and prompted significant activity in developing and understanding the psychophysics of the baggage detection process.

In the US the SPEARS (Screener Proficiency Evaluation and Reporting System) had already been piloted at 19 major US airports prior to the 9/11 attacks (Neiderman \& Fobes, 1997). SPEARS involved a number of perceptual test to identify individuals with aptitude to the screening task, and also to help train those who would go on to become baggage inspection officers. The SPEARS system operated visually in a similar manner to the current X-ray Tutor, or XRT (also discussed later in this section), in that it superimposes threat objects into benign baggage images, with increasing levels of difficulty. In 1998 the FAA announced it would use SPEARS for training and that it may be used by airlines to aid the recruitment of suitable screening staff. This was succeeded by the Threat Image Projection (TIP) system (Singh and Singh, 2003) which can randomly project threat objects from a large database numbering several thousand. TIP was planned to be a standard feature integrated into all Xray baggage inspection systems used in US airports by 2003. One of the standard methods for assessing baggage screener competency in the US was to subject screeners to the Competency Assessment Test (CAT), wherein a linear relationship has been found between hit rate and decision time (Wales et al 2009).

Parallel activity over the last decade or more in Europe has seen the development of several different tests for screeners including the Object Recognition Test (ORT) and the Prohibited Item Test (PIT). The PIT is used to establish whether a screener understands what items are prohibited and what items are accepted. It consists of a set of images of knives, sharp objects guns and explosives, and is designed to assess the knowledge component of a screener's skill set. By contrast the ORT is designed to assess the detection abilities of a screener to bag complexity. These factors have been broadly associated with three main image-based factors: bag complexity, superposition, and viewpoint of the target. (Schwaninger, 2004, 2005). Mendes \& Schwaninger (2010) have subsequently demonstrated that 'ability', as measured by performance, of X-ray screening observers depends on two key factors: the individual's inherent ability to perform a the screening task, coupled with the quality, and level of, training 
that the individual has received. Such training may take the form of on-the-job training as well as classroom based computer-based training. The latest training aid, X-ray Tutor (XRT) is one such tool that may be used to superimpose threat objects onto X-ray images of normal benign luggage. XRT delivers a graded training environment that increase with difficulty as the observer's performance during training increases (Mendes \& Schwaninger, 2010). In the US, one of the standard methods for assessing baggage screener competency is to subject screeners to the Competency Assessment Test (CAT) (Wales et al, 2009).

Investigating the effectiveness of training of screening expertise has attracted considerable scientific interest. Several studies have considered the differences between naïve or untrained observer performance when compared with that of trained observers using eye-tracking to analyse the observer's behaviour (Liu et al, 2007). In simulated inspection tests, screeners were, perhaps unsurprisingly, found to operate more efficiently than naïve observer's in scene scanning and determining a decision, employing more developed search strategies than the naïve individuals. Liu \& Gale (2011) also found that trained observers were faster at detecting threats and more accurate. However it was noted that both groups performed badly at detecting IEDs, even though the trained observer's eye dwelled on the threat, but invariably ignored it, underlining the need for appropriate training on this, the most difficult of threats for detection. This was also supported by other prior work (Wales et al., 2009), showing similar reductions when the detection task becomes more challenging (i.e. baggage image complexity increases), with poorest performance demonstrated for IEDs which do not exhibit such regular image-based features as other threat objects such as guns and knives.

It is thought that there are three basic image-based factors that will govern an individual's performance: viewpoint, or orientation of the threat object with respect to the observer, superposition (of other objects over/under the threat object) and the complexity of the X-ray screeners being observed (Mendes \& Schwaninger, 2010). Tests undertaken with staff from European airports suggests, perhaps unsurprisingly, high correlations of performance in XRT and scores obtained in the X-ray Competency Assessment Test (X-ray CAT) which is used for officers to gain accreditation at several European airports.

In order to aid decision support, artificial colour may be used to highlight potential threats. McCarley, (2009) has described the work of different types of performance aids on the baggage screening detection task by varying the detection thresholds of these aids. They found that human performance was dramatically improved with the use of an appropriate aid, which is ascribed to the operators willingness to take action based on the aid's diagnosis, the results of which may be used to enhance the effectiveness of effective detection automatic aids in the future. Decision pertinence critically dependent on quality of information provided 
during screening process. Potential performance can be improved by enhancing the performance of on-screen aides, via the development of improved features and classification performance (Singh \& Singh, 2003). Relatively poor performance has been found with monochrome screens, as used by Fobes' (1995) and others in earlier assessment work, which can be largely attributed to the limitations of the then available technology.

Further recent work (Al-Fundi et al, 2009) has also found that observer performance is significantly improved when appropriate colour is used to highlight potential threats. However, the same authors also highlight some of the limitations of the highly idealised signal detection theory framework used to derive ROC features: in-situ baggage screener performance can deteriorate due to a number of real-life factors such as vigilance state, personnel issues, or surrounding environmental factors (e.g. noise), which can adversely affect the performance obtained in a 'test' situation.

\section{$4 \quad$ X-ray Radiographic Principles}

\subsection{The Detection Problem}

The use of x-ray technology for inspection of bulky items is entirely predicated on the penetrating nature and material-discriminating capability of energetic $\mathrm{x}$-rays, checked baggage being a prime example of such need. Of course, before understanding why this characteristic behaviour should be so, it first needs to be acknowledged that practical implementation of an x-ray inspection system is only a reality because of a number of remarkable technological developments that make possible a high throughput, high sensitivity screening arrangement. Central among these developments is the compact, high-flux x-ray source, most often but not exclusively an evacuated glass or more recently a metal-ceramic tube (sometimes referred to as the envelope) x-ray system that comprises a hot electronemitting cathode and a cooled high melting point target anode of high atomic number ( $\mathrm{Z}$ ). This ensures an abundant flux of x-rays while limiting power load damage to the envelope and anode, damage to the latter resulting from the desire to have fine focal spot and hence high spatial resolution capability. The supply of power is in turn provided by a highly stabilised generator giving rise to an accelerating potentials and $\mathrm{mA}$, the choices of which are suited to the imaging quality and throughput, limited by the thermal rating of the tube. Finally, and in the very broadest of terms, the system is made complete by provision of a high efficiency 2-D detection system the design of which is appropriate for a given spatial resolution, the latter also being influenced by the focal spot defined by the focused tube arrangement and associated power loading. Fig 5 shows a schematic of a standard projection 
radiography set up, the development of which has been influenced by the various factors discussed above and also by hardening filters and grids, the latter inhibiting receipt of imageobfuscating scattered radiation at the imaging plane.

Enormous efforts have been expended in trying to confront the very many factors that reduce performance, including exploratory designs of for instance liquid metal anodes. The latter is intended to avoid the surface damage of solid anode systems, the extent of which becomes more pronounced with age, broadening the focal spot thereby decreasing spatial resolution. For an excellent discussion of the foregoing, refer to Medwow (2011).

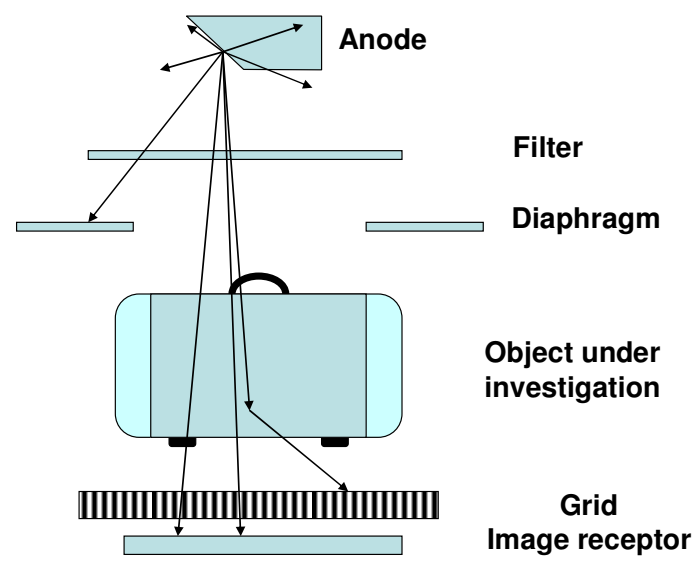

Fig 5. Schematic of a standard projection radiography set up providing for imaging of bulky items, the incident beam being filtered to obtain a 'hardened' penetrating beam and the exit beam passing through a grid to reduce reduction of image quality by scattered radiation.

With the above situation now established, one can return to the penetrating nature and material-discriminating capability of energetic x-rays. The x-ray imaging dependencies are intimately related with the fact that $\mathrm{x}$ (and gamma-rays) interact weakly with matter via the electromagnetic force, the associated limited energy loss per unit path length, otherwise known as the linear energy transfer, LET, being typically expressed in $\mathrm{keV} \mu \mathrm{m}^{-1}$. This provides for the penetrating capability, four principal attenuation mechanisms reducing the $\mathrm{x}$ ray flux of a confined beam of photons that transport through a given medium to go towards forming the conventional transmission image. There are two scattering and two absorption processes, each with approximate 'characteristic' dependencies on photon energy, atomic number and mass density, these being the elastic (Rayleigh) and inelastic (Compton) 
scattering processes and the photoelectric and pair production absorptive processes. The nonanalytic (hence approximate) dependencies most typically quoted are shown in Table 4 below, for atomic numbers up to $\mathrm{Z} \approx 20$; also included in the table are the approximate energy ranges over which a given mechanism will dominate over other attenuation processes. In each case, these various processes involve interactions with the electrons in the medium of interest and hence the strength of interaction is dependent upon physical density and thus electron density. For the myriad possible multi-element compounds and mixtures, the resultant mass attenuation coefficient, normalised for density $\rho$, is given by:

$$
\frac{\mu}{\rho}=w_{1} \frac{\mu_{1}}{\rho_{1}}+w_{2} \frac{\mu_{2}}{\rho_{2}}+\ldots
$$

where $w_{1}$ etc represent the weight fraction of a constituent element and $\mu_{1} / \rho_{1}$ etc, the respective mass attenuation coefficients.

At this point it is pertinent to mention that, with the exception of the elastic photon scattering process, the remaining photon reducing (atomic) processes provide for photon reduction only. As we will discuss later, in addition to reduction in the number of photons transported through a given medium, the elastic scattering process is also sensitive to molecular and textural features of the target, interference and diffraction giving rise to a modulated $2 \mathrm{D}$ pattern. To-date much less attention has been paid to the elastic scattering process for baggage inspection than the other primary interaction processes, its utility often being confined to much lower photon energies (eg the $8.04 \mathrm{keV} \mathrm{Cu} \mathrm{K \alpha}$ radiation used most notably in crystallographic investigations) suitable only for very thin objects, $\leq 1 / \mu$.

Table 4: Photon interaction dependencies upon energy and atomic number

\begin{tabular}{|l|c|c|c|}
\hline Mechanism & Variation with E & $\begin{array}{c}\text { Variation with } \\
\mathbf{Z} \text { (for } \mathbf{Z} \leq \mathbf{2 0} \text { ) }\end{array}$ & $\begin{array}{c}\text { Energy- } \\
\text { dominating } \\
\text { range }\end{array}$ \\
\hline Rayleigh & $\propto 1 / \mathrm{E}$ & $\propto \mathrm{Z}^{2}$ & $1-30 \mathrm{keV}$ \\
\hline photoelectric & $\propto 1 / \mathrm{E}^{3}$ & $\propto \mathrm{Z}^{3}$ & $1-100 \mathrm{keV}$ \\
\hline Compton & $\begin{array}{c}\text { falls gradually with E, with } \\
\text { probability given by Klein- } \\
\text { Nishina cross-section. }\end{array}$ & Independent & $0.5-5 \mathrm{MeV}$ \\
\hline $\begin{array}{l}\text { Pair } \\
\text { production* }\end{array}$ & $\begin{array}{c}\text { rises slowly with E above the } \\
\text { interaction threshold energy of } \\
2 m_{e} c^{2} \text { (i.e. twice the electron rest } \\
\text { mass }=1.022 \mathrm{MeV} \text { ) 21 }\end{array}$ & $\propto \mathrm{Z}^{2}$ & $>5 \mathrm{MeV}$ \\
\hline
\end{tabular}

* Not accessed in current or presently foreseen checked baggage systems, due to the limited detection efficiency and available contrast. 
Table 5: Typical values of $\mu$ and $H_{1 / 2}$ for monoenergetic radiations

\begin{tabular}{|c|c|c|c|c|c|}
\hline $\begin{array}{l}\text { Energy } \\
(\mathrm{keV})\end{array}$ & Material & $\begin{array}{l}\text { Atomic } \\
\text { number }\end{array}$ & $\begin{array}{l}\text { Density } \\
\left(\mathrm{kg} \mathrm{m}^{-3}\right)\end{array}$ & $\begin{array}{l}\mu \\
\left(\mathbf{m m}^{-1}\right)\end{array}$ & $\begin{array}{l}\mathbf{H}_{1 / 2} \\
(\mathbf{m m})\end{array}$ \\
\hline 30 & \multirow[t]{3}{*}{ Water } & \multirow[t]{3}{*}{7.5} & \multirow[t]{3}{*}{$10^{3}$} & 0.036 & 19 \\
\hline 60 & & & & 0.020 & 35 \\
\hline 200 & & & & 0.014 & 50 \\
\hline 30 & \multirow[t]{3}{*}{ Aluminium } & \multirow[t]{3}{*}{13} & \multirow[t]{3}{*}{$1.27 \times 10^{3}$} & 0.160 & 4.3 \\
\hline 60 & & & & 0.050 & 13.9 \\
\hline 200 & & & & 0.020 & 35 \\
\hline 30 & \multirow[t]{3}{*}{ Lead } & \multirow[t]{3}{*}{82} & \multirow[t]{3}{*}{$11.4 \times 10^{3}$} & 33 & $2 \times 10^{-2}$ \\
\hline 60 & & & & 5.5 & 0.13 \\
\hline 200 & & & & 1.1 & 0.6 \\
\hline
\end{tabular}

In regard to transmission radiography, for photon energies up to $200 \mathrm{keV}$ (above which image contrast reduces significantly, as discussed below, and also because radiation shielding of the inspection facilities becomes more cumbersome), Table 5 provides indicative penetration capabilities, both in terms of the combined linear attenuation coefficient, taking account of the weight fractions for compounds.

X-ray inspection systems display gray-scale images, representing variations in the shape, thickness and composition of an object, reflected in the attenuation coefficient. As an example, for a 5 bit digital detector 32 gray-scale levels are available, while for a 10 bit detector, the gray-scale levels are stretched to 1024 distinct gradations. The so-called contrast variations contained within a transmission image represents the relative change in attenuation between one part of a medium and another. Thick, high-density, high- $Z$ features produce greater reduction in photon flux than thin, low density, low atomic number objects, as reflected in the associated image. As such, within certain limits of detection it is possible to quantitatively measure these features and develop correlations that reflect a decision threshold. A particular limitation of such absorptiometry in examining for evidence of the low $\mathrm{Z}$ constituents of for instance explosives is the limited variation in physical density, $\rho$, of 
such substances. This becomes clear in application of the Beer-Lambert law (exact for monoenergetic incident radiation and single scattering events), as follows:

$$
I=I_{0} \exp (-\mu t) \quad(2)
$$

$I_{0}$ representing the incident photon intensity and $I$ the intensity transmitted through a medium of linear attenuation coefficient $\mu$, thickness $t$. Rewriting this in terms of the mass attenuation coefficient, $\mu_{m}$, yields:

$$
\begin{aligned}
& I=I_{0} \exp \left(-\mu_{m} \rho t\right) \\
& \text { with } \mu_{m}=\frac{\mu}{\rho}
\end{aligned}
$$

The measurement sensitivity is obtained as the differential of (2):

$$
\frac{d I}{d \rho}=-\mu_{m} t I_{0} \exp \left(-\mu_{m} \rho t\right)
$$

which, in substituting from (2), gives $\frac{d I}{d \rho}=-\mu_{m} t I$

As such, it is apparent that sensitivity to change in density is greatest for large $\mu_{m}$, large path length and large flux, none of which might be expected to apply in regard to concealed explosives.

\subsection{Present challenge: HMEs and their precursors.}

A summary of some of the better known bomb threats against civil airliners, all of which are in the public domain is shown below in Tables $6 \mathrm{a}$ and $6 \mathrm{~b}$. 
Table 6a. Selection of HMEs of recorded use in terrorist activity. (Information obtained from readily available internet sources.)

\begin{tabular}{|c|c|c|c|}
\hline $\begin{array}{c}\text { Short- } \\
\text { form } \\
\text { name }\end{array}$ & Full name & Description & $\begin{array}{l}\text { Terrorist } \\
\text { Incident }\end{array}$ \\
\hline Semtex & & $\begin{array}{l}\text { General purpose } \\
\text { plastic explosive, } \\
\text { produced by mixing } \\
\text { RDX and PETN (see } \\
\text { below) with small } \\
\text { amounts of binder, } \\
\text { platicizer antioxidant } \\
\text { and dye. } \\
\text { Distinctive vapour. }\end{array}$ & Lockerbie (1988) \\
\hline $\begin{array}{l}\text { TATP } \\
\text { TACP }\end{array}$ & $\begin{array}{l}\text { Acetone Peroxide } \\
\text { triacetone } \\
\text { triperoxide, peroxyacetone }\end{array}$ & $\begin{array}{l}\text { White crystalline } \\
\text { powder } \\
\text { Acrid odour } \\
\text { Unstable to heat, } \\
\text { friction and shock }\end{array}$ & $\begin{array}{l}\text { Transatlantic } \\
\text { bomb plot (2006) } \\
\text { Shoe bomber } \\
\text { (with PETN) } \\
(2001)\end{array}$ \\
\hline $\begin{array}{l}\text { PENT, } \\
\text { PETN } \\
\text { PENTA } \\
\text { TEN } \\
\text { Nitropenta }\end{array}$ & Pentaerythritol tetranitrate & $\begin{array}{l}\text { Granulated to mimic } \\
\text { toner powder density } \\
\text { (NB: toner powder } \\
\text { typically a melt-mix of } \\
\text { carbon with a polymer) }\end{array}$ & $\begin{array}{l}\text { As above } \\
\text { Printer cartridge } \\
\text { bomb plot ( } 2010) \\
\text { in granulated } \\
\text { form }\end{array}$ \\
\hline $\mathrm{H}_{2} \mathbf{O}_{2}$ & Hydrogen Peroxide & $\begin{array}{l}\text { Simplest peroxide } \\
\text { Clear colourless liquid, } \\
\text { when diluted } \\
\text { Used in bleach and in } \\
\text { rocketry }\end{array}$ & $\begin{array}{l}\text { Used with } \\
\text { acetone } \\
\text { Transatlantic } \\
\text { bomb plot (2006) } \\
\text { 7/7 London } \\
\text { bombings } \\
\text { Shoe bomber } \\
\text { (with PETN) } \\
\text { (2001) }\end{array}$ \\
\hline $\begin{array}{l}\text { Baratol } \\
\text { Octogen } \\
\text { HMX }\end{array}$ & $\begin{array}{l}\text { Octahydro-1,3,5,7- } \\
\text { tetranitro-1,3,5,7- } \\
\text { tetrazocine } \\
\text { High Melting Explosive } \\
\text { Her Majesty's Explosive } \\
\text { High Velocity Military }\end{array}$ & $\begin{array}{l}\text { Nitroamine high } \\
\text { explosive }\end{array}$ & Military use \\
\hline
\end{tabular}




\begin{tabular}{|c|c|c|c|}
\hline & $\begin{array}{l}\text { Explosive } \\
\text { High Molecular Weight RdX }\end{array}$ & & \\
\hline $\begin{array}{l}\text { ANFO } \\
\text { AN/FO }\end{array}$ & $\begin{array}{l}\text { Ammonium Nitrate }\left(\mathrm{NH}_{4} \mathrm{NO}_{3}\right) \\
\text { with } \\
\text { Fuel Oil } \\
\text { e.g. heating oil, diesel fuel, } \\
\text { kerosene }\end{array}$ & $\begin{array}{l}\text { Stable solid. } \\
\text { Burns. } \\
\text { Only explodes when } \\
\text { used with detonator. } \\
\text { Relatively shock proof. }\end{array}$ & $\begin{array}{l}\text { Mining/Quarrying } \\
\text { Prov IRA (1972) } \\
\text { Bishopsgate } \\
\text { bombing (1993) } \\
\text { Oaklahoma City } \\
\text { Bombing (1995) } \\
\text { Taliban IEDs } \\
(2009)\end{array}$ \\
\hline $\begin{array}{l}\text { RDX } \\
\text { Cyclonite } \\
\text { Hexogen } \\
\text { T4 }\end{array}$ & cyclotrimethylenetrinitramine & & $\begin{array}{l}\text { Bombay (1993) } \\
\text { Mumbai Train } \\
\text { bomb (2006) } \\
\text { Moscow Metro } \\
(2010)\end{array}$ \\
\hline
\end{tabular}

The variation in density of HMEs often depends sensitively on the manufacturing route. illegal bomb manufacturers seem to be well aware of how x-ray screening equipment works and in as far as it is possible they would probably be seeking to tailor their technology so that the device would become undetectable, particularly in regard to the familiar x-ray transmission imaging systems.

Hydrogen peroxide (density for a $30 \%$ solution, $1.110 \mathrm{~g} \mathrm{~cm}^{-3}$ at $20 \mathrm{deg} \mathrm{C}$; density for pure $\mathrm{H}_{2} \mathrm{O}_{2}, 1.450 \mathrm{~g} \mathrm{~cm}^{-3}$ at $20 \mathrm{deg} \mathrm{C}$ ) appears to be the pre-cursor of choice at the current time, having also been the main ingredient in the 7 July 2005 London bombings that killed 52 London Underground and bus passengers. It has been reported that the bomb-making ingredients have been easier to buy than large numbers of pills (BBC News, 2011). Following the London transatlantic plot of 2006, in which hydrogen peroxide was thought to have been mixed during flight with a fuel such as acetone to create an explosive mixture, passengers have been required to remove liquids from their hand luggage prior to boarding.

In view of the foregoing observations, several solutions have been proposed to address the challenge of liquid identification for security screening, including Raman scattering, nuclear quadrupole resonance, and ion mobility spectrometry, to mention but a few likely candidates. Unfortunately these approaches are not generally applicable and can fail when used for instance on hermetically sealed vacuum flasks. It is clearly desirable that the introduction of technological solution should enable the end user to maintain current tactics, techniques and 
procedures without major changes to their current practices. Before looking at some possible solutions for liquids, the predominant current $\mathrm{x}$-ray imaging practices are first reviewed below.

Table 6b. Selection of explosives and precursor explosive media, ordered by effective atomic number, $Z_{\text {eff, }}$ for the penetrating $\mathrm{x}$-ray energy range of interest, together with the number of contributing electrons per atom of $\mathrm{C}, \mathrm{H}, \mathrm{N}, \mathrm{O}$, total number of electrons per molecule, $\mathrm{n}_{\mathrm{e}}$ and mass density, $\rho_{\text {rel }}$, relative to water. Also included are a number of harmless media for which discrimination through use of $\mathrm{x}$-ray absorptiometry may be challenged.

\begin{tabular}{|c|c|c|c|c|c|c|c|c|}
\hline & Nature & C & $\mathbf{H}$ & $\mathbf{N}$ & 0 & $\mathbf{n}_{\mathbf{e}}$ & $Z_{\text {eff }}$ & $\rho_{\text {rel }}$ \\
\hline Polyethylene & Polymer & 2 & 4 & & & 16 & 5.5 & $\sim 0.9$ \\
\hline PMMA & Polymer & 5 & 8 & & 2 & 54 & 6.5 & 1.18 \\
\hline $\begin{array}{l}\text { Acetone peroxide: } \\
\text { TATP (dimer) }\end{array}$ & Explosive & 6 & 12 & & 4 & 80 & 6.7 & 0.7 \\
\hline $\begin{array}{l}\text { Acetone peroxide: } \\
\text { TATP (trimer) }\end{array}$ & Explosive & 9 & 18 & & 6 & 120 & 6.7 & \\
\hline HMTD & Explosive & 6 & 12 & 2 & 4 & 94 & 6.8 & 0.9 \\
\hline Sorbitol & Sugar & 6 & 14 & & 6 & 98 & 6.9 & 1.5 \\
\hline Uric acid $\left(\mathrm{C}_{5} \mathrm{H}_{4} \mathrm{~N}_{4} \mathrm{O}_{3}\right)$ & Precursor & 5 & 4 & 4 & 3 & 86 & 6.9 & 1.9 \\
\hline Sugar (Saccharose) & Sugar & 12 & 22 & & 11 & 182 & 6.9 & 1.6 \\
\hline Fructose & Sugar & 6 & 12 & & 6 & 96 & 7.0 & 1.5 \\
\hline Delrin & Polymer & 1 & 2 & & 1 & 16 & 7.0 & 1.4 \\
\hline TNT & Explosive & 7 & 5 & 3 & 6 & 116 & 7.1 & 1.7 \\
\hline $\begin{array}{l}\text { Ammonium picrate } \\
\text { (Dunnite) }\end{array}$ & Explosive & 6 & 6 & 4 & 7 & 126 & 7.2 & 1.7 \\
\hline Nitromethane & Explosive & 1 & 3 & 1 & 2 & 32 & 7.2 & 1.1 \\
\hline Cyclonite (RDX) & Explosive & 3 & 6 & 6 & 6 & 114 & 7.2 & 1.8 \\
\hline HMX (Octogen) & Explosive & 4 & 8 & 8 & 8 & 152 & 7.2 & 1.9 \\
\hline Nitrocellulose & Explosive & 6 & 7 & 3 & 11 & 152 & 7.3 & 1.3 \\
\hline PETN (Penthrite) & Explosive & 5 & 8 & 4 & 12 & 162 & 7.4 & 1.8 \\
\hline Ammonium nitrate & Explosive & & 4 & 2 & 3 & 42 & 7.4 & 1.8 \\
\hline $\mathrm{H}_{2} \mathrm{O}$ & Water & & 2 & & 1 & 10 & 7.4 & 1.0 \\
\hline $\mathrm{H}_{2} \mathrm{O}_{2}$ & Precursor & & 2 & & 2 & 18 & 7.7 & 1.5 \\
\hline $\mathrm{H}_{2} \mathrm{O}_{2}(1 / 3)+\mathrm{H}_{2} \mathrm{O}(2 / 3)$ & Precursor & & & & & & & \\
\hline Black Powder* & Carboniferous & & & & & & & 0.9 \\
\hline Chlorate powder $\left(\mathrm{ClCO}_{3}\right)$ & Inorganic salt & & & & & & & 1.45 \\
\hline C4 (RDX + Liant) & Explosive & & & & & & & 1.4 \\
\hline Semtex & Explosive & & & & & & & 1.48 \\
\hline Dynamite & Explosive & & & & & & & 1.4 \\
\hline
\end{tabular}

*Mixture of potassium nitrate, charcoal and sulphur: 75\%/15\%/10\%;http://www.simulants.co.uk/Explosives$\underline{\text { Lexicon.htm }}$

Note that for some compounds (e.g. TATP) the physical density can vary dramatically, depending on the manufacturing method, challenging density-based detection methods. 


\section{Current X-ray techniques}

There exists particular advantages or disadvantages of the two predominant approaches to $\mathrm{x}$ ray imaging that lead to the formation of either $2 \mathrm{D}$ or $3 \mathrm{D}$ images. The conventional $2 \mathrm{D}$ transmission approach (see below) clearly provides a great deal of information concerning particular characteristics of a given object including location, orientation and volume but undoubtedly suffers from the fact that overlying or underlying features may mask the presence of potential threats. In other words, a weak feature in one plane may be obscured by a strong feature in another. In addition, a transmission radiograph gives no information about the depth of a feature. Hence, on face value it would appear that there is an overwhelming need to obtain the image of an isolated slice using techniques that would effectively dissect it from potential obfuscating feature-laden layers, above or below. This brings about the idea of harnessing what is now known as tomosynthesis or simply CT imaging (again see below). However, conventional X-ray computed tomography has the drawback of not being materialspecific and it also cannot distinguish between liquids and solids. The reality is that the additional information gained may not be commensurate with the expense and effort required to capture the image.

For a detailed review of the developments of x-ray imaging techniques over the past several decades, the interested reader is directed to the work of Gray and Tillack (2001), Martz et al. (2010) focusing on industrial applications and Harding (2004) focusing on explosives detection.

\subsection{Planar radiography}

In planar radiography (see Fig. 6), including laminography, otherwise known as tomography (see later), the image is formed in a receptor (as for example a flat panel detector) positioned on the obverse side of an object to that of the source.

Here, an object represented by a function $f(x, y, z)$ is imaged as a projection $P(x, y)$ onto the $\mathrm{x}$,y plane, given by $P(x, y)=\int_{0}^{t} f(x, y, z) d x$, where $t$ is the thickness of the object. Hence, the $\mathrm{x}$ and $\mathrm{y}$ coordinates of a feature are retained but the z-coordinate is lost.

The conventional system is relatively insensitive to small changes in contrast, a contrast change of the order of at least $2 \%$ to $5 \%$ being necessary with usual receptors in order that it may be recognised as distinct. For carboniferous media (with an effective atomic number of 
7 and density similar to water), the changes in contrast between differing parts of such an object are usually well below this limit and hence conventional radiographic techniques are inadequate for such media.

As we have heard, an obvious problem in conventional radiography is the superimposition of compositional variations within the object under study. The issue has lead to the development of various x-ray methods of depth determination. One method, limited in reality to single well-defined features, is that of rotation of coordinates. One such approach is the creation of orthogonal images, typically anterior-posterior and lateral views, as these are generally referred to in medical terminology. Another is stereoscopy in which two images displaced by just a few degrees are produced (Fig. 6). The separate images can be viewed in a stereoscope. Given a separation of x-ray tube and imaging receptor of $\mathrm{D}$ and a tube shift $\delta t$ an image shift of $\delta x$ is produced such that a feature located at an intermediate distance $\mathrm{z}$ from the receptor between the receptor and focal spot can be shown to be given by:

$$
z=\frac{D \times \delta x}{\delta t+\delta x}
$$

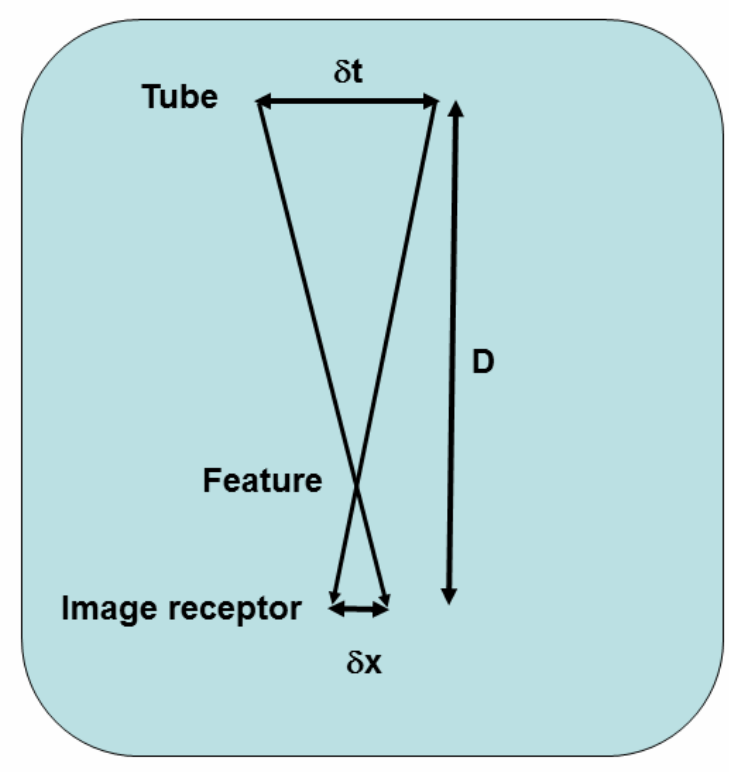

Fig 6. The basic principle of a rectilinear tomographic scanning system, the function of which is to ensure the blurring out of projection details lying outside of the imaging plane (the tube and imaging receptor moving in straight lines both normal to the axis of the imaging system). Other possible movements include curvilinear (the tube and imaging receptor moving in matching arcs) and pluridirectional paths (the tube and imaging receptor moving in circular, elliptic, hypocycloidal, spiral, sinusoidal or random path, in an effort to avoid non image feature related structural features . 
The mechanism for moving the focus and the detector must ensure that the images of all points contained in a given plane must lie on the same set of points on the detector. In short, off-axis imaging can be utilised as described, favourably positioning the sample device or assembly at angles to the x-ray source. The image can be examined with the appropriate application of algorithms, as above, such that one may be able to locate and log suspicious areas. The main feature provided by this type of radiographic system is shape information. It is difficult to derive quantitative density information owing to the presence of disturbing material elsewhere in the suitcase.

Tomography represents yet another special radiographic technique that has been brought to bear in overcoming the superimposition problem through rotation of coordinates, the imaging receptor and x-ray tube being moved continuously in opposite directions over a limited range. In this method, only features in a plane containing the fulcrum remains stationary while movement unsharpness blurs out the image of other parts of the object located above or below the stationary layer. The thickness of section remaining in focus depends on the angle of traverse and the resolution required.

\subsection{X-ray CT (rotating and fixed gantry)}

In the 1970s, the use of digital computers in conjunction with ionisation or scintillation counters ushered in a new era in x-ray radiography particularly suited to imaging of low atomic number media (in particular for soft tissue imaging in clinical situations and subsequently in industrial materials inspection such as cementatious materials). At the very essential level, a narrow beam is made to traverse the object under study and then through an exit collimator that has been carefully aligned to allow it to be received by a detector. The pencil beam is made to be rotated around the object, the transmitted beam falling on a detector array, overcoming the superimposition problem and providing for detection of variations in the linear attenuation coefficient of low atomic number media of as little as $0.05 \%$ (Fig. 7). 


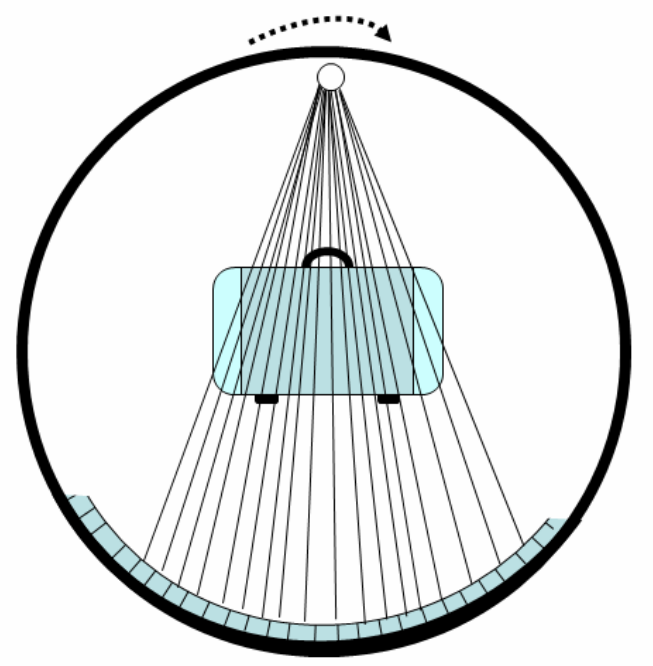

Fig. 7. Schematic of a Real-Time Tomography (RTT) CT device. Many x-ray sources around the circumference of the device are sequentially activated to produce a fan beam of radiation that effectively rotates around an axis perpendicular to the plane of the paper surrounded by a ring of detectors to provide for rapid scanning rates.

This ability arises from the fact that the range of numbers corresponding to the attenuations along a beam direction is spread electronically (referred to as windowing).

Here we consider a section through the object of interest, represented by a two-dimensional array of attenuation coefficients $f_{m, n}$. In this array there are a total of $\mathrm{M} \times \mathrm{N}$ unknown values.

The attenuation suffered by a narrow beam of $\mathrm{x}$-rays traversing one row of the array, is given by:

$$
\exp -\left(f_{1, n}+f_{2, n}+f_{3, n}+\ldots \ldots \ldots \ldots+f_{M, N}\right)
$$

The natural logarithm of the beam intensity will then be proportional to:

$$
\left(f_{1, n}+f_{2, n}+f_{3, n}+\ldots \ldots \ldots \ldots+f_{M, N}\right)
$$

By passing the beam through every element of the array in many different directions, one can obtain $\mathrm{M} \times \mathrm{N}$ simultaneous equations and solve for all $\mathrm{M} \times \mathrm{N}$ unknowns. This method is too cumbersome for practical applications, so a method using Fourier transforms is used instead. 
In practical systems, the output of the detector is fed through the usual nuclear electronics to a fast computer. The system offers high sensitivity, high resolution (sub $\mathrm{mm}$ ), quantitative output and a complete absence of superposition.

Martz and Crawford (2011) have observed that the CT scanners used to detect explosives in checked and carry-on baggage are generally very similar to medical imaging single- and dualenergy multi-slice CT scanners. Among those devices recently developed for explosives detection some employ multiple sources and detector arrays to eliminate mechanical rotation of a gantry and also photon counting detectors for spectral imaging. Crawford and Martz add that the need for a more limited number of views reduces cost.

CT delivers the spatially-resolved density distribution as its main information. Thus both the density and shape/volume are helpful features in discriminating between harmless and threat material.

\subsection{Dual- and multi-energy imaging}

In dual-energy imaging measurement is made at different $\mathrm{X}$ - ray energies of the difference in attenuation of a simple two component system (Fig. 8).

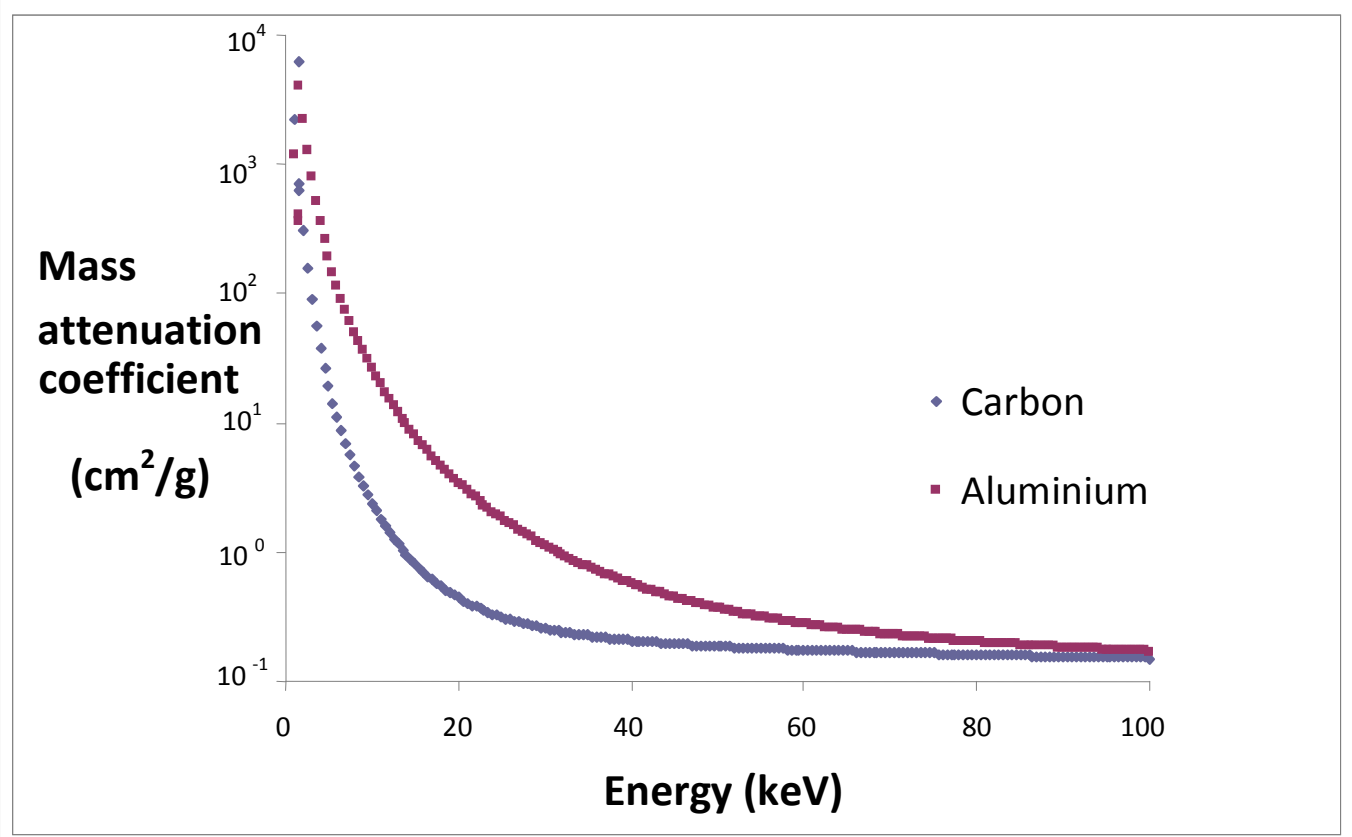

Fig 8. Energy dependence of the mass attenuation coefficients of carbon and aluminium adapted from NIST Tables of Hubbell et al. 
Assuming monoenergetic radiation and that no scattered radiation is detected, then the transmitted radiation intensity through a region of components $a$ and $b$, acquired at a low Xray energy and following logarithmic transformation, is given by:

$$
I_{l o}=\mu_{a, l o} x_{a}+\mu_{b, l o} x_{b}
$$

where:

- $\quad \mu_{a, l o}$ is the linear attenuation coefficient of component $a$ at the low X-ray energy;

- $x_{a}$ is the thickness of component $a$;

- $\quad \mu_{b, l o}$ is the linear attenuation coefficient of component $b$ at the low X-ray energy; and

- $x_{b}$ is the thickness of component $b$.

Similarly, the transmitted radiation intensity for the same region of an image acquired at a higher X-ray energy is given by:

$$
I_{h i}=\mu_{a, h i} x_{a}+\mu_{b, h i} x_{b} \quad(10)
$$

where:

- $\quad \mu_{a, h i}$ is the linear attenuation coefficient of component $a$ at the higher X-ray energy; and

- $\quad \mu_{b, h i}$ is the linear attenuation coefficient of component $b$ at the higher X-ray energy.

When these images are multiplied by separate weighting factors, $k_{l o}$ and $k_{h i}$ and the result combined to form a composite image, the output image is given by:

$$
I=k_{l o} I_{l o}+k_{h i} I_{h i}
$$

Therefore $I=\left(k_{l o} \mu_{a, l o}+k_{h i} \mu_{b, h i}\right) x_{a}+\left(k_{l o} \mu_{b, l o}+k_{h i} \mu_{b, h i}\right) x_{b} \quad,(12)$, which indicates that cancellation of component $a$ can be achieved by setting the coefficient of $\mu_{a, h i}$ equal to zero, i.e.

$$
k_{l o} \mu_{a, l o}+k_{h i} \mu_{a, h i}=0
$$


Thus,

$$
k_{l o} \mu_{a, l o}=-k_{h i} \mu_{a, h i}
$$

and

$$
\frac{k_{h i}}{k_{l o}}=-\frac{\mu_{a, l o}}{\mu_{a, h i}}
$$

which indicates that component $a$ can be eliminated from the composite image when the ratio of weighting factors in equation (1) above is chosen to equal the negative of the ratio of the attenuation coefficients of component a at the two X-ray energies. A similar approach can be used to cause cancellation of component $b$ by setting the coefficient of $x_{b}$ in equation (1) to zero.

Of course, it is a potentially small step from application of the above to use of x-ray fluorescence x-ray tubes (Harding et al., 1991) for possible combined CT-multiple energy xray imaging systems that further improve detail detectability (Fig. 9).

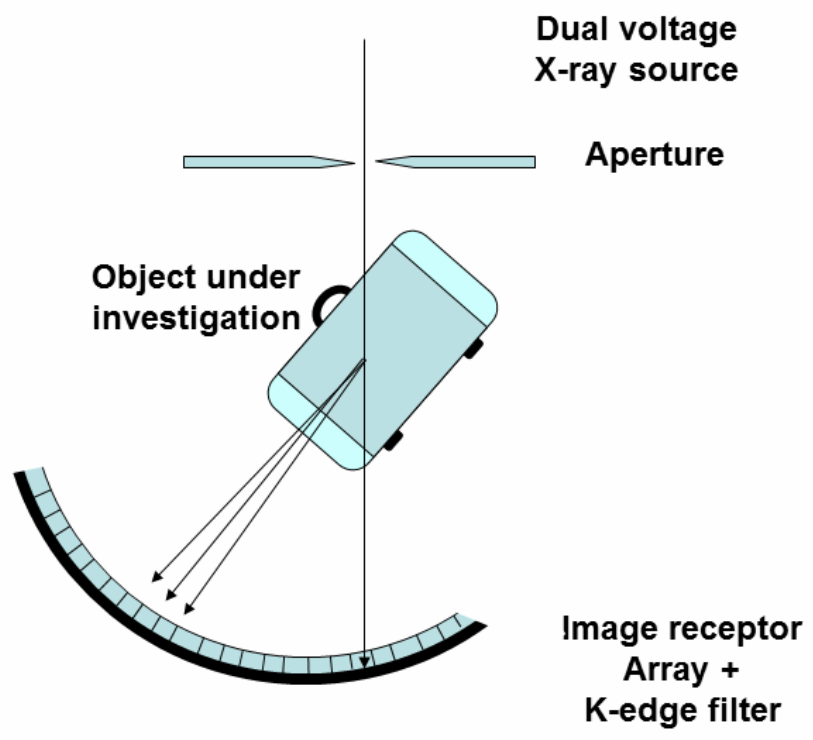

Fig. 9. Schematic of a potential combined CT-multiple energy x-ray imaging system to further improve upon detail detectability

Attempts to gain spectral information by separating raw bremsstrahlung spectra into photoelectric effect and Compton scattering dominated energy regions is not new (see for instance, Alvarez et al., 1976; Kelcz et al.,1979; Lehmann et al., 1981). Here it is recognized that, for the typical wide energy bremsstrahlung spectrum provided by CT scanners, the Compton interaction dominates the total attenuation coefficient $\mu_{T}$ at the higher photon 
energies $\left(\mu_{T} \propto \rho\right)$ while at the lower photon energies the total attenuation coefficient $\mu_{T}$ is dominated by the photoelectric absorptive dependence $\left(\mu_{T} \propto \bar{z}^{3.5} \rho\right), \bar{z}$ representing the effective atomic number of a homogenous multi-elemental medium.

Dual-energy x-ray imaging can be accomplished by varying the potential of the x-ray tube, by arranging for the beam to be recorded in sandwich detectors (Knoll, 2000), which have different sensitivities to high and low energy photon beams, or through the use of so-called Kedge filters. In x-ray beams filtered by elemental media, discontinuities become apparent in the attenuation coefficients, photons of energy corresponding to the minimum binding energy of electrons, being just sufficient for ejection of the electrons. Thus, for instance, just above the binding energy of K-shell electrons, the electrons enjoy an elevated probability of absorbing photons compared to the sub-threshold photon energies. The photon energy at which the sudden change in absorption probability occurs is referred to as the K-edge, the associated differential absorption being sufficient to partition the original spectrum into high and low energy components. In terms of practical applications, the approach suffers from the limited energy resolution offered by the K-edge filters and also from photon starvation, the latter leading to elevated noise levels in the raw images particularly if multi-element filters are used to further decompose the raw spectrum into several quasi monoenergetic regions. The consequence of such filtration is a demand for more powerful $\mathrm{x}$-ray sources and hence greater shielding.

Features that can be extracted from dual-energy CT scans include the spatial distributions of both the (electron) density and the mean atomic number variations. Hence all other things being equal a dual-energy CT scanner could be expected to have a ROC detection performance that is superior to a single-energy scanner type, simply because it delivers more physical features.

\subsection{Backscatter Techniques}

In this technique Compton backscattered photons are observed using a detector array placed on the same side of the object under investigation as the source (Harding and Kosanetzky, 1989), see Fig.10. The registered back scattered events effectively reveal the difference between the Compton scattering cross-sections of the prevailing medium and scanned objects within it. This can be used to reproduce the shape of such details. Among the advantages of the technique are included reduction in superimposition and an ability to image objects in situations in which the far side of an item is inaccessible. 
Underpinning the method is the fact that for an incident photon of energy $h v$, photons scattered through an angle $\theta$ are reduced in energy to $h v^{\prime}$ according to the kinematic relation:

$$
h v^{\prime}=\frac{h v}{1+\frac{h v}{m c^{2}}(1-\cos \theta)}
$$

with $h$ the Plank constant.

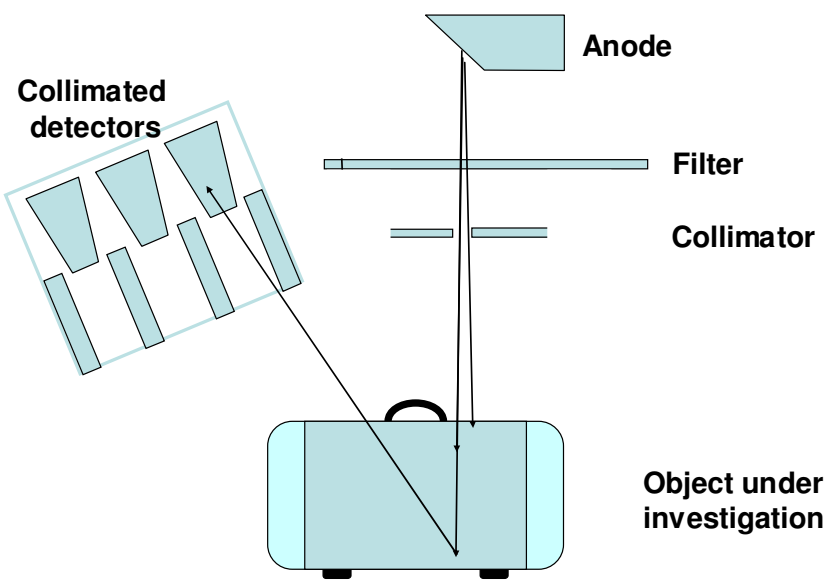

Fig.10. Schematic of a backscattering geometry situation.

In addition, the number of inelastically scattered photons observed at a scattering angle $\theta$ can be calculated through application of the Klein-Nishina $(\mathrm{KN})$ cross-section, the probability being differential with the solid angle $d \Omega=2 \pi \sin \theta d \theta$ subtended by the detector at the scattering angle $\theta$ :

$$
\left(\frac{d \sigma}{d \Omega}\right)_{K N}=\frac{1}{2} r_{e}^{2} f(\varepsilon, \theta)^{2}\left[f(\varepsilon, \theta)+f(\varepsilon, \theta)^{-1}-\sin ^{2} \theta\right]
$$


where $r_{e}=\frac{e^{2}}{m c^{2}}=2.818 \times 10^{-13} m$ is the classical electron (Bohr) radius, $\varepsilon=\frac{h v}{m c^{2}}$ is the incident photon energy normalised to the rest energy of the electron, and $f(\varepsilon, \theta)=\frac{1}{1+\varepsilon(1+\cos \theta)}$.

For a given attenuator, the intensity of Compton backscattered photons reduces with increase in photon energy and in part for this reason the practical applications of Compton back scattering measurements have been limited. The geometry further dictates that greatest sensitivity of detection is obtained at the superficial or surface-level than more deeply embedded material within a package.

The backscattering technique is one offering shape and spatial distribution of features, being only dependent upon electron density.

\section{$5.5 \mathrm{X}$-ray diffraction imaging}

Until the most recent of times, the Rayleigh scattering process has largely been ignored as an imaging modality. This might be considered surprising given that elastic photon-atom scattering provides for $\mathrm{x}$-ray crystallography, perhaps most famously being intimately linked with the discovery of DNA. As will be learned later, the imaging challenge lies in the fact that at penetrating photon energies Rayleigh scattering is very much confined to the forward direction.

As a process, Rayleigh scattering is mediated by electrons in inter-mediate bound and continuum states, the original electronic configuration being restored upon completion of the elastic scattering process. It would appear that the first measurements of elastic scattering in liquids were those due to Friedrich et al. in 1913, x-ray diffraction patterns being obtained for Canada balsam, paraffin and amber. As described, and cited, by Gingrich (1943), in 1916 Debye and Scherrer obtained diffraction patterns for several liquids, including benzene, while in 1922, Keesom and de Smedt reported work of this type for liquid elements. Bernal and Fowler (1933) provided one of the earliest detailed discussions of the structure of water, the study being based on x-ray diffraction measurements carried out by workers over the period 1930 to 1931 for a range of temperatures.

While in principle the oganizational characteristics of any radiologically thin medium can be obtained from interference of elastically scattered photons (including for short-range ordered media such as water, ammonia and polymeric substances such as polymethylmethacrylate, 
nylon, cheese and Semtex), in practice its observation is almost entirely dependent upon the detailed performance of the measurement set-up, the correlation between scattering centres becoming more forward peaked with increase in photon energy. Measurements of Rayleigh scattering represent much less of a technical challenge now than was perhaps true some two decades ago. The accuracy and precision of differential scattering evaluations have improved significantly with the availability of higher intensity point sources, optimised set-ups and higher resolution detectors; it is now typical to claim uncertainties in measurement of the order of $5 \%$ or less. Thus, at the higher photon energies required for penetration of substantial objects ( up to a few $\mathrm{cm}$ ), various media of interest in medical physics have now been investigated through use of Rayleigh scattering as has development of security systems, including those for detection of explosives, drug shipments etc. In association with this, in situations in which detection efficiency is not a controlling factor, small-dimension Peltiercooled semiconductor detectors have been found to be of utility. One example of such a detector is $\mathrm{Cd}_{0.9} \mathrm{Zn}_{0.1} \mathrm{Te}(\mathrm{CZT})$. Peltier-cooled semiconductor detectors improve on the resolutions offered by scintillation crystals, and offer a portability not enjoyed by the liquid nitrogen ( $\mathrm{LN}$ ) cooling systems. This is also true of position-sensitive detectors, sometimes referred to as area detectors, including digital devices such as CMOS and charge-coupled devices (CCDs) and pixelated slabs of solid-state detector materials. These types of detector have become of increasing importance in studies of low-momentum transfer scattering distributions from amorphous targets. In particular, the low momentum transfer scattering intensity distribution can be captured in one simultaneous measurement. One of the earliest reports concerning use of such a device was that of Dupont et al. (1972), x-ray diffraction study being made of the kinetics of lipids in E. Coli. More recently, amorphous semiconductors, an example of which is amorphous selenium (a-Se), have been reported to be under active development for use in digital x-ray imaging (Rowlands and Kasap, 1997). New, creative set-ups might be expected with further developments in this fast moving area of detector technology.

From the beginning of the 1980s, with progress being made in new radiological modalities, including mammography and interest in new image correction methods, renewed interest was shown in the scattering amplitudes of low energy photons for low $\mathrm{Z}$ media. Measurements of angular distributions of scattered photons, mainly for water, the most used of all phantom media for soft tissues, were reported by a number of workers, use being made of $\mathrm{x}$-ray tubes and radioactive sources (Johns and Yaffe, 1982, 1983; Evans et al., 1991). A schematic of one such arrangement can be seen in Fig 9. 


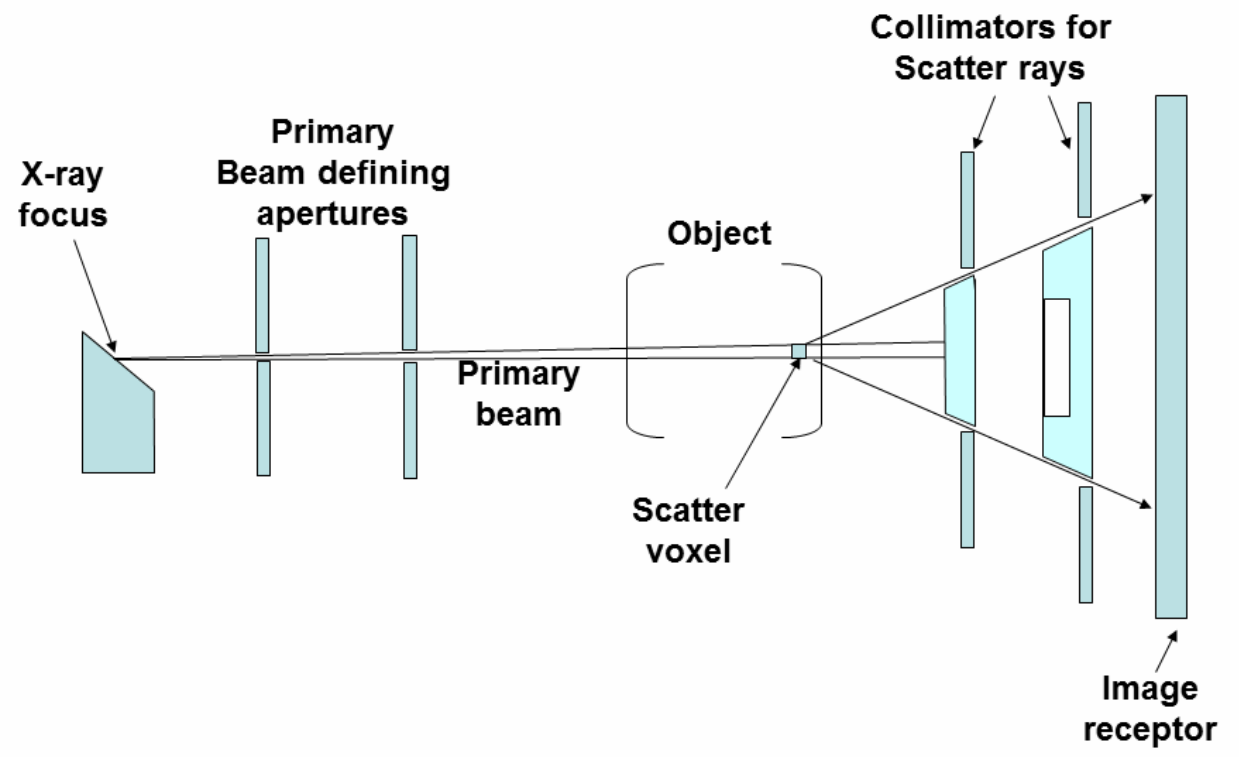

Fig 11. Simple schematic arrangement for capture of small-angle elastic scattering events, limited for illustrative purposes to a particular scattering angle. An imaging detector would need to provide for spectroscopic capability in order to select out the elastic scattering signal from inelastic events. A rather more challenging but not insuperable task is to fabricate and characterize the performance of a multi-hole collimator system that would allow the obtaining of the desired elastic scattering profile of an object (i.e for a range of small scattering angles), captured simultaneously. See also figures 12 and 13, below.

Co-operative work between medical and radiation physicists saw the development of a number of creative and original studies, using detectors such as film (Johns and Yaffe,1982), semiconductors (Cheng and Holloway, 1995), CT detectors (Johns and Yaffe, 1983) and multi-wire cameras (Bradley et al., 1989). Harding et al. (2007a,b) have recently considered such a technique for the material-specific identification of solid-state explosives and narcotics in hold luggage, seeking to eliminate the inconvenience, uncertainty, and expense associated with monitoring liquids separately from hand luggage at checkpoints. The application of XRD imaging to security screening has so far been limited to organic explosives. However, the potential of this technique for identifying liquids still remains to be tapped. 


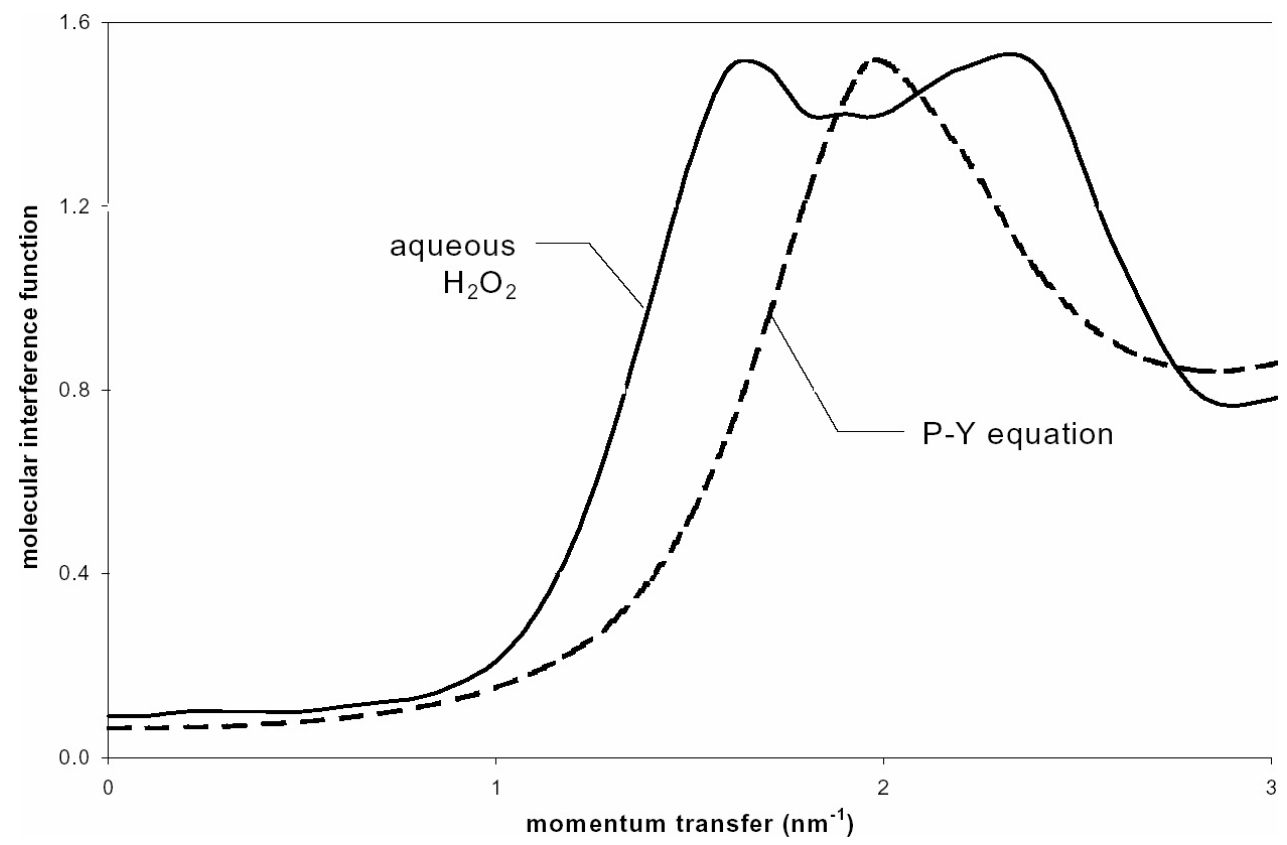

Figure 12. Comparison of molecular interference function for $30 \%$ by volume aqueous $\mathrm{H}_{2} \mathrm{O}_{2}$ solution (solid line) with Percus-Yevick (P-Y) plot (dashed line), defined by parameters $\mathrm{R}$ and $\varphi$, determined by equating curve height and peak position with that of a water curve. Harding (2007a).

The XRD profiles of liquids can be described as the product of three factors (Harding and Harding, 2007; Hukins, 1981). These include the x-ray scattering from a single, unbound electron, the so-called Thomson cross-section, modification of the Thomson cross-section to account for the spatial structure of atomic orbitals (atomic form factor), and the spatial correlations between neighbouring atoms originating in the molecular structure of the liquid. The technique adopted by Harding is based on determining this last factor, called the molecular interference function (MIF), where MIF depends on momentum transfer, and is closely related to the radial distribution function (RDF) that describes the spatial distribution of electronic charge throughout a liquid. In principle, at least, the RDF and associated MIF can be considered the 'fingerprints' of the liquid that they can help to identify. 


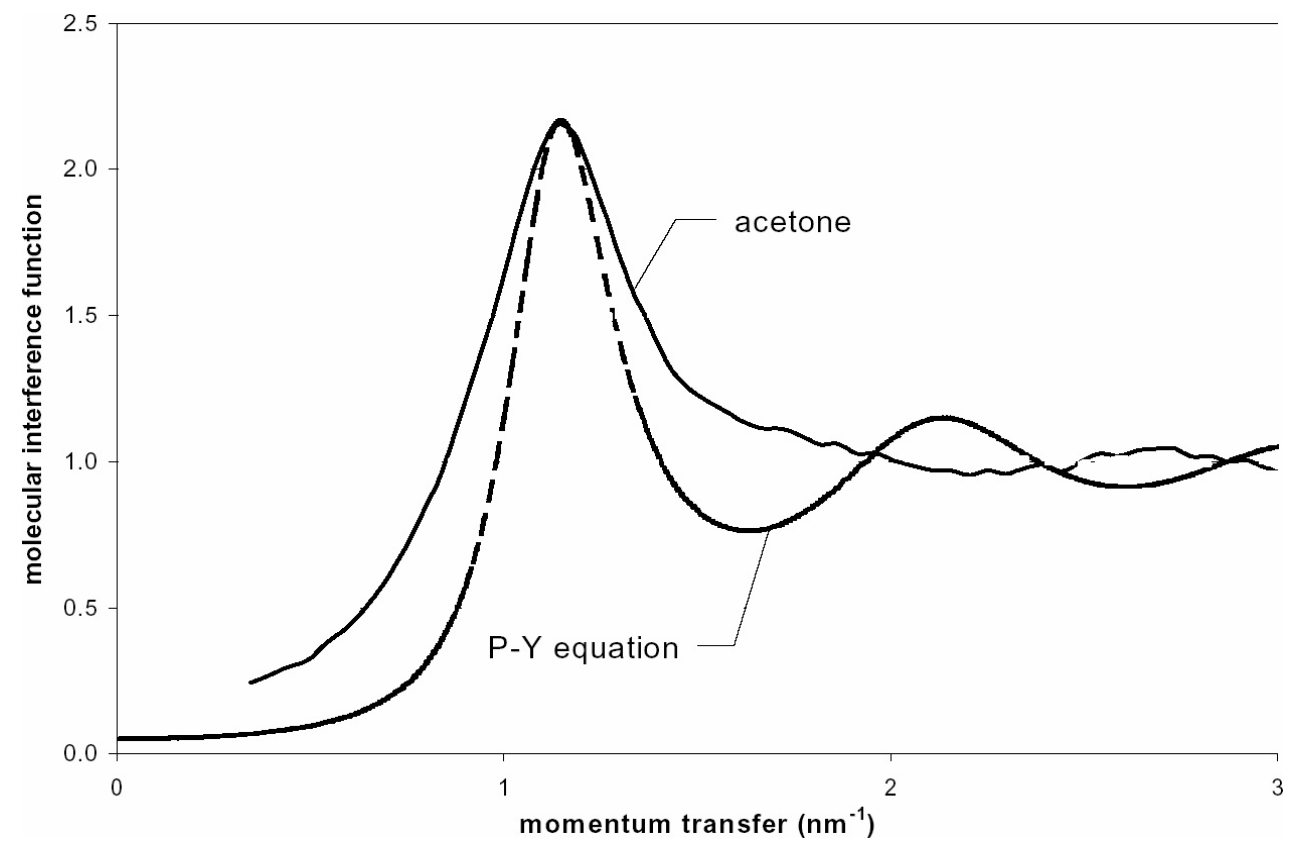

Figure 13. Molecular interference function for acetone (solid line) and best fit to the P-Y function (dashed line), normalized to the maximum experimental peak height and position (Harding 2007a).

The authors have considered a hypothetical liquid consisting of hard spheres, interacting only to exclude one another from the space occupied by each. Under such circumstance, Hukins (1981) has shown that the MIF can be calculated using the so-called Percus-Yevick equation, expressed as a function of the sphere diameter, $R$, and the packing fraction, $\Phi$ that determines the fraction of the total volume occupied by the spheres. Synchrotron X-ray diffraction (XRD) measurements performed on two liquid samples, an aqueous hydrogen peroxide solution and acetone, are shown in Figures 12 and 13, respectively, the degree of interference being plotted against the momentum transfer, $x=\frac{\sin (\theta / 2)}{\lambda}$. These liquids are representative of the majority of current oxidizer-fuel combinations. For comparison purposes, the best fit to the Percus-Yevick MIF is also shown. The aim of such work is to establish XRD as a 'onestop' screening technique, valid for the full range of explosives, including crystalline, amorphous, liquid, and home-made explosives.

As has been explained, a detection modality becomes fully characterized only when its receiver operating characteristic (ROC) is known. The ROC analysis of XRD-based liquid screening now requires an extensive, long-term systematic study, currently being initiated.

The number of physical features delivered by XDI is in principle greater than that of $\mathrm{x}$-ray transmission techniques, as the former accesses a new dimension of information; namely the 
distribution of $\mathrm{x}$-ray scattering resolved along the momentum transfer axis. Typical XRD plots of crystalline materials display characteristic Bragg peaks, whose positions are a "signature" for the material under investigation. Similarly XRD analysis of liquid samples provides a significant number of features for liquids classification, notwithstanding the fact that the diffraction peaks are much broader than in the crystalline case. It is to be noted here that while whole baggage screening for liquids is not yet a security checkpoint, it is nevertheless expected to become so in the not too distant future.

\section{Future Horizons for X-ray-based Inspection}

\subsection{Phase contrast imaging}

As mentioned above, conventional X-ray Computed Tomography is often considered to provide the state of the art in capturing small differences in the associated attenuation coefficients. However set against this is the reality that, for low atomic number media, differences in X-ray absorption may be so weak that the diagnostic information contained in the image contrast will be too low to be useful. This may include radiologically thin threat material. During the last decade, a number of novel methods have been developed in the field of X-ray imaging that are based on wave properties of X-rays (see for instance, Wilkins, 1996; Fitzgerald, 2000; Gundogdu et al., 2007). In order to perform X-ray phase contrast imaging, the coherence of the X-ray beam used is an important factor in determining the quality of the images obtained, since it is the coherence that allows the wave phenomena of interference and diffraction to be utilised for high energy X-ray photons. A simplified way to describe the behaviour of photons in matter is provided by the refractive index, $n$, where:

$$
n=1-\delta+i \beta
$$

with $\delta$ the real dispersive part of the refractive index and $\beta$ the imaginary absorptive part. The passage of photons through a medium will result in absorption and a change in the phase of the wavefront. As an example of utility, $20 \mathrm{keV}$ X-rays that pass through a $50 \mu \mathrm{m}$ thick sheet of biological tissue are attenuated by only a fraction of a percent, whilst the phase shift is close to $\pi$ (Weitkamp et al., 2005).

A wide range of threat materials of interest can be expected to exhibit weak X-ray attenuation but yet still produce significant phase shifts at the same X-ray wavelengths. The use of phase information for imaging purposes therefore represents a potentially attractive prospect. As such, in imaging low atomic number media, recording the X-ray phase shift instead of the 
absorption substantially increases the contrast. As a consequence, several phase-sensitive Xray imaging methods have been developed in recent years. There are three main experimental methods which are used for X-ray phase imaging, these are:

- Phase Propagation,

- Diffraction-enhanced (using an analyser crystal), and

- Interferometer methods.

In regard to potentially practical imaging devices, phase propagation offers perhaps the greatest potential (see Fig. 14).

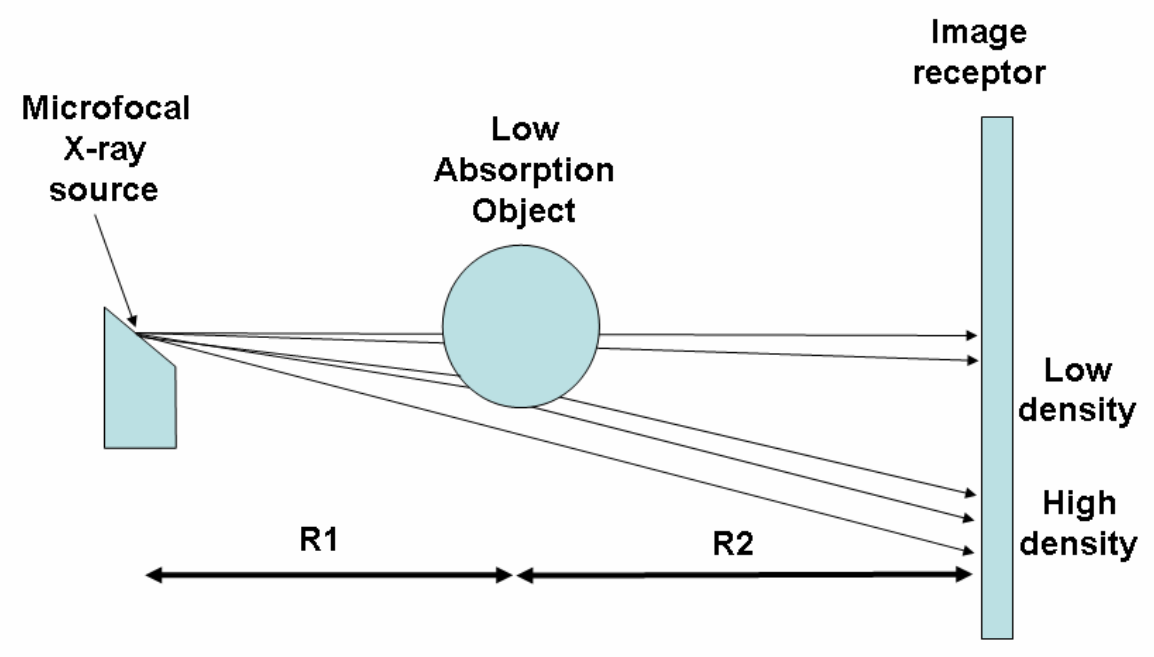

Fig 14. Illustration (not to scale) of phase contrast imaging and edge effect with a microfocal $\mathrm{X}$-ray point source. The imaging receptor is set at a sufficiently large distance from the low absorption contrast object of interest to allow capture of the elastically scattered photons that dominate the scattering events in the forward direction. As such, on the edge of this low absorption contrast feature, edge enhancement takes place due to refraction of the $\mathrm{x}$-rays, leading to significant phase contrast (Matsuo et al. 2004). $R I$ is the distance between the source and the object and $R 2(>>R 1)$ that between the object and detector.

Phase information retrieval is easier with low energy X-ray photons, a large source to object distance and a small source size (Lewis 2004). Temporal coherence or monochromaticity is not essential and as such phase contrast imaging can also be performed with polychromatic radiation (Wilkins et al. 1996). The employing of a microfocal spot x-ray tube places the greatest limitation on performance, the system being relatively slow and only suitable for radiologically thin media, a situation in which multiple scattering dominated by inelastic scattering is limited. Thus said, it can also be noted that the use of a microfocal x-ray unit 
provides for a considerable degree of magnification, allowing finer structural details to be observed and a greater uniformity of depth of focus to be attained, compared against that attainable using conventional projection radiography.

Technological solutions that may make for more rapid screening could perhaps include a robust high output microfocal spot $\mathrm{x}$-ray tube, operational at higher $\mathrm{kVps}$ than is currently the case. Alternatively, Olivo et al. (2011) have proposed a coded aperture concept in which use is made of conventional x-ray sources without the need to collimate the output.

\subsection{Doppler Broadening}

The Doppler broadening suffered by Compton scattered X-rays results from the momentum distribution of the atomic electrons with which these X-rays interact (Cooper, 1985). The phenomenon, firmly established by experiment and widely exploited in condensed matter physics in studying electronic properties, has been described by among other Ribberfors (1987) and Matscheko et al. (1989).

Relation (17) can be re-written in terms of the wavelength shift $\Delta \lambda$, such that:

$$
\Delta \lambda=\frac{\hbar}{m c}(1-\cos \theta)
$$

The manifest line broadening, not described in relation (19), was observed by Du Mond (1930) to result from the initial momentum distribution of the electrons. Indeed, if the electrons are assumed to be free but non-stationary, one can then obtain a description of the Doppler broadening of the scattered radiation as a correction to relation (19), as follows:

$$
\Delta \lambda=\frac{\hbar}{m c}(1-\cos \theta)-\frac{2 \lambda}{m c} \sin \left(\frac{\theta}{2}\right) p_{z}(20),
$$

with $P_{z}$ the component of the electron momentum parallel to the scattering vector. The free electron Compton differential-in-angle Klein Nishina cross section described in relation (18) follows from the assumption of free stationary electrons. If one allows for binding in a nonrelativistic treatment then one obtains the photon-electron interaction Hamiltonian:

$$
H_{\mathrm{int}}=\frac{(e \mathbf{A})^{2}}{2 m}-e \frac{\mathbf{p . A}}{m}
$$


where $\mathbf{A}$ is the electric field vector potential. The first term dominates for energies greatly in excess of electron binding energies. The term containing p.A becomes increasingly important for decreasing photon energies such that binding effects can no longer be ignored. The differential cross-section for Compton scattering by a bound electron can be written as:

$$
d^{3} \sigma=r_{e}^{2} \frac{\omega_{2}}{\omega_{1}}\left|M_{f i}\right|^{2} d \omega_{2} d \Omega d \Omega_{\varepsilon}
$$

where $\left|M_{f i}\right|$ is the matrix element for the process. Almost all non-relativistic evaluations of bound electron Compton scattering are based on the form factor approximation of $M_{f i}$, where:

$$
M_{f i} \approx\left(\varepsilon_{1} \cdot \varepsilon_{2}\right)\left\langle f\left|e^{i k . r}\right| i\right\rangle
$$

and $\varepsilon_{1}$ and $\varepsilon_{2}$ are the respective polarisation of the initial and final photons, of momenta $k_{1}$ and $k_{2}$. For the whole atom the basic picture is that provided by an independent particle approximation in which excitation or ionization involves one electron with all other electrons left undisturbed. The inelastic scattering function is obtained by summing for each of the electrons of the atom, taken separately. Integrating over scattered final photon energies $\omega_{2}$ gives:

$$
\left(\frac{d \sigma}{d \Omega}\right)_{\text {inelastic }}=\left(\frac{d \sigma}{d \Omega}\right)_{K N} \frac{\omega_{2}}{\omega_{1}}\left(\sum\left\langle i\left|e^{i q \cdot\left(r_{i} \cdot r_{j}\right)}\right| j\right\rangle-F\left(q^{2}\right)^{2}\right)
$$

where $F\left(q^{2}\right)$ is the atomic form factor (Hubbell et al., 1975).

Electron binding is taken into account through the so-called incoherent scattering function $S(x, Z)$, increasing from 0 at $\theta=0$ to 1 for large momentum transfers, $x$. Thus the Klein Nishina cross-section is usually corrected for binding by multiplying by the incoherent scattering function:

$$
\left(\frac{d \sigma}{d \Omega}\right)_{\text {inelastic }}=\left(\frac{d \sigma}{d \Omega}\right)_{K N} S(x, Z)
$$

where $Z$ is the atomic number of the target atom.

Within the approximation in which energy transfer is assumed to be large compared to electron binding energies (the so-called impulse approximation) the spectral distribution of 
scattered photons can be related to the momentum distribution of bound electrons $J\left(p_{Z}\right)$, manifest as the Compton profile (i.e. the Compton line-shape), providing:

$$
\frac{d^{2} \sigma}{d \Omega d \omega_{2}}=\frac{1}{2}\left(1+\cos ^{2} \theta\right) r_{e}^{2} \omega_{2} \frac{J\left(p_{Z}\right)}{k \omega_{1}}
$$

The relationship between $P_{Z}$ and $\omega_{2}$ is given by:

$$
p_{Z}=\gamma\left[\omega_{1}-\omega_{2}\right]-\frac{\omega_{1} \omega_{2}(1-\cos \theta)}{\left(\omega_{2}^{2}+\omega_{1}^{2}-2 \omega_{1} \omega_{2} \cos \theta\right)^{1 / 2}}
$$

with $\gamma=m c^{2}\left(1+\frac{p_{Z}^{2}}{2 m}\right) \approx m c^{2}$ representing the relativistic energy of the scattered electron. The Compton profile measurement technique finds application as a probe of the ground state electron density of various systems (see for instance, Cooper, 1985). In particular, it can be shown that:

$$
J\left(P_{Z}\right)=\int_{p_{x}} \int_{p_{y}} n\left(p_{x}, p_{y}, p_{z}\right) d p_{x} d p_{y}
$$

where $n\left(p_{x}, p_{y}, p_{z}\right)$ is the electron momentum distribution of the scatterer.

Advances in measurement capability have depended in large part upon development of high intensity monoenergetic sources, higher resolution detectors and a greater ability for acquisition and processing of data. However, recent advances (Hubert Chen et al., 2004; Yadav et al., 2005) now make the Doppler broadening phenomenon observable in Compton scattering spectrometers that are equipped with room-temperature semiconductor detectors, such as $\mathrm{Cd}(\mathrm{Zn}) \mathrm{Te}$. .

This Doppler broadening effect (Fig. 15) is expected to offer significant diagnostic information for X-ray based material characterization. 


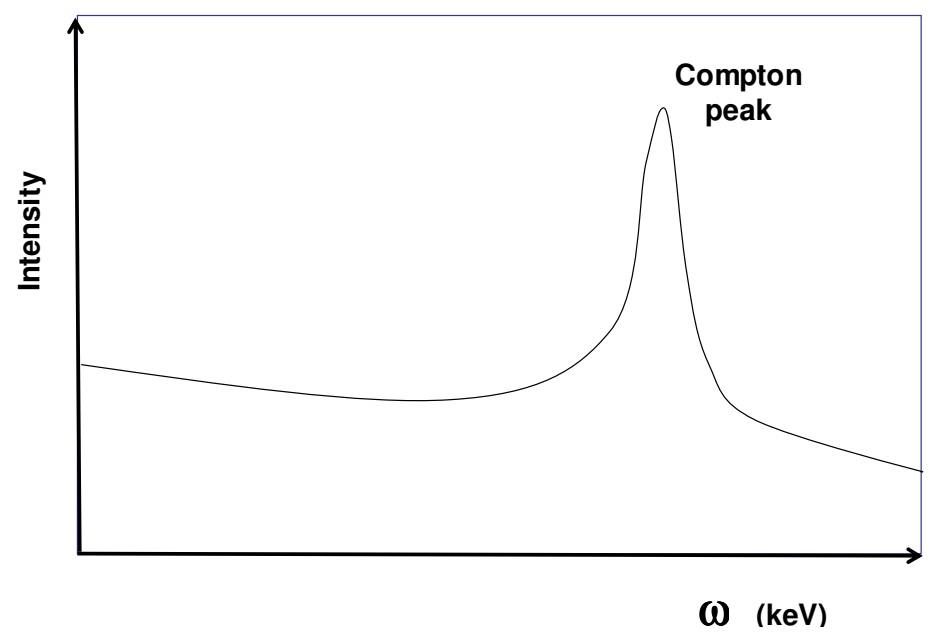

Fig. 15. The line-broadened Compton profile, dependent on: local electron density; local attenuation coefficient; and energy width of the tube target $\mathrm{K} \alpha$ line. This is a particular profile, for a particular scattering angle. The suggestion is to use Doppler broadening for liquid screening of smaller objects (viz for bottle scanning). Advantages are availability of tomographic information and a triplet of features, as listed above. Limitations include need for high energy resolution detectors and (as with all x-ray scatter techniques!) measurement time.

\subsection{Spectroscopic / Photon Counting}

One of the latest and still developing technologies for CT imaging is that of the ultra-fast Xray photon counter. As the fluence in a single X-ray pulse is very large, then an efficient imaging sensor has to have extremely high count rate capability. For example the (scintillator/CMOS-based) X-Pad exhibits a high-counting rate over $10^{9}$ photons/pixel $/ \mathrm{mm}^{2}$ (Fibril et al, 2006). Other examples also exist, such as the Medipix sensor originally developed at CERN (e.g. Ponchut, et al, 2002), and the ChromAIX system developed for medical CT (Hermann et al, 2010), with potential application in this area . Alternatively, $\mathrm{CdTl}$ has been proposed as a photon counting alternative (Rebuffel et al, 2007), as has GaAs photon counting (Přibi et al, 2009) although issues of carrier recombination and relatively slow drift velocities may compromise this type of technology in this ultra-fast counting regime (although such technology may also well be suited to backscatter security methods).

These pixelated photon counting devices open up the possibility of energy discrimination with CT imaging. Although not widely available at the current time, one might envisage 
energy-resolved CT. If so then energy band-pass images of the scanned target can be made available, and then potentially used to infer absolute Z. However, one might wish for a higher performance than has so far been realised in order to improve Contrast to Noise and throughput performance, particularly as scanned dose is not a primary issue in the security arena.

Nonetheless, early results with simple phantoms and a set of pre-determined energy windows have shown promising results (Feuerlein, et al, 2008), although there are considerable difficulties to be overcome before this approach can be used routinely in either a clinical or a security screening context. For example, the extreme operating conditions, wherein the detector must respond from an almost zero count rate to maximum count rate, then pulse pileup may lead to count rate losses and spectral distortion (Wang et al, 2011).

\section{Conclusions}

The development of baggage screening technology, and methodology, has developed hand-inhand with the ever changing security needs of modern air travel. This article has considered the baggage screening technology, and decision-making principles, employed in the EU and US, which in both sectors of the aviation scene, have been subject to detailed scrutiny since the $9 / 11$ terror attacks. This tragic event has also been the force majeure behind dramatic improvements in the performance of automatic screening technologies and high-throughput systems. One might speculate this represents the start of an upward trend in imaging technology along with enhanced machine and observer-based decision making principles, as manufacturers and academia seek to exploit new aspects of the physics of the detection process, coupled with advances in the computer vision and psycho-perception communities in making smarter decision-making systems that will compliment and re-enforce the role of the expert screening officer.

We leave the reader with three additional thoughts: (a) the density feature at the heart of x-ray transmission imaging is becoming increasingly inadequate to distinguish between threats and non-threats owing to the widespread use of HMEs; (b) the larger the number of independent features that a technique delivers, then the better, in general, will be its ROC performance; (c) $\mathrm{x}$-ray scatter techniques offer in principle more features than does transmission as long as the basic limitation of long measurement times can be overcome. 


\section{Acknowledgement}

The authors gratefully acknowledge permission from the SPIE to reproduce Figures 12 and 13 taken from original SPIE publications of Harding et al. 


\section{References}

Al-Fandi, L., Mabe, N. \& Khasawneh, M.T., 2009. The impact of threat type and image color on baggage screening performance: A Preliminary investigation; APIEMS, pp $2432-2437$.

Alvarez, R.E., Macovski, A., 1976. Energy-selective reconstructions in x-ray computerized tomography. Phys Med Biol. 21, 733-744.

Barrat, H.H. Handbook of Medical Imaging; 2000. SPIE Press, Bellingham, Washington

Bernal, J.D., Fowler, R.H., 1933. A theory of water and ionic solution, with particular reference to hydrogen and hydroxyl ions. J. Chem. Physics 1, 515-548.

Bishop, C.M., 2007. Pattern Recognition and Machine Learning; Springer; ISBN-10: 0387310738

Bjorkholm, P.J., 2004. Dual energy detection of weapons of mass destruction; Port technology International; P122 - 6/4, pp 1- 3

Blalock, G., Kadivall, V., Simon, D.H., 2007. The impact of post 9/11 airport securtity measures on the demand for air travel; Journal of Law \& Economics. Available at SSRN: http//ssm.com/abstract=1007534 / doi 10.2139/ssm.677563

Boeing Company Report. 2009.

http://www.boeing.com/commercial/safety/pf/pf_howsafe.html

Bradley, D.A., Dance, D.R., Evans, S.H., Jones, C.H., 1989. A study of molecular correlation observed in the small-angle photon scattering distributions of $60 \mathrm{keV}$ photons interacting with low-atomic-number media. Nucl. Instr. Meth. Phys. Res A280, 380-383.

BBC News website, 2011. http://www.bbc.co.uk/news/uk-12337575

Bretz, E.A., 2002. Delayed Arrival for US Baggage Screening?; IEEE Spectrum, May 2002 pp 16-19

Bretz, E.A., 2002. Slow takeoff (airport security; IEEE Spectrum magazine; Vol, 39, Issue 9 pp 37-39

Butler, V. and Poole, R.W., 2002. Rethinking checked baggage screening. Reason Public Policy Institute Policy Study 297

Cooper, M.J., 1985. Compton scattering and electron momentum determination. Rep. Prog. Phys. 48, 415. 
Doherrty, R., 2009. Detection of Homemade Explosives; U.S. Department of Homeland Security, Science and Technology (S\&T) Directorate; Available at http://www.dhs.gov/xlibrary/assets/st_detect_and_defeat_hme.pdf

Du Mond, J. W. M., 1930. Multiple Scattering in the Compton Effect, Phys. Rev. 36, 16851701.

Dupont, Y., Gabriel, A., Chabre, M., Gulik-Krzywicki, T., Schechter, E., 1972. Use of a new detector for x-ray diffraction and kinetics of the ordering of the lipids in E. coli membranes and model systems. Nature 238, 331- 333.

ECORYS, 2009.Study on the Competitiveness of the EU security industry Within the Framework Contract for Sectoral Competitiveness Studies - ENTR/06/054. Final report. Nov. 2009.http://ec.europa.eu/enterprise/policies/security/files/study_on_the_competitiveness_of_t he_eu_security_industry_en.pdf

Evans, S.H., Bradley, D.A., Dance, D.R., Bateman, J.E., Jones, C.H., 1991. Measurements of small-angle photon scattering for some breast tissues and tissue-substitute materials. Phys. Med. Biol 36, 7-18.

Fitzgerald R., 2000. Phase-Sensitive X-Ray Imaging, Physics Today 53, 23.

Fobes, J.L., McNuity, D.M., Neiderman, E., Klock, B. A. \& Barrientos, J.M., 1995. Test and Evalution Report for the Explosive Device Detection Baseline Study; 1995; DOT/FAA/AR95/16 Final Report, December 1995.

Fobes, J.L. \& Klock, B. A., 1995. Test \& Evaluation Plan for the Explosive Device Detection Baseline (EDDB) Study; 1995; DOT/FAA/AR-95/16, August 1995

Friedrich, W., Knipping, P., and Laue, M., 1913. Interference appearances in x-rays. Ann. Phys.-Berlin, 41:971-988. Reprinted from Sitzungsber. K. Bayer. Akad. Wiss. pp. 303-322, (1912).

Feuerlein, S., Roessl, E., Proksa, R,, Martens, G.,, Klass, O., Jeltsch, M., Rasche, V., Brambs, H-J., Hoffmann M H. K., and Schlomka, J-P. 2008. Multienergy Photon-counting K-edge Imaging: Potential for Improved Luminal Depiction in Vascular Imaging. Radiology. 249, $1010-1016$.

Geo Robson \& Co (Conveyors) Ltd; Hold Baggage Screening Systems in Airport International.com; 2011. http://www.airport-int.com/article/hold-baggage-screeningsystems.html 
Gingrich, N. S., 1943. The diffraction of x-rays by liquid elements. Revs. Modern Phys.15, 90.

Gray, J. and Tillack G-R., 2001. Review Of Progress In Quantitative Nondestructive Evaluation, AIP Conf. Proc., 557, 16-32. doi:10.1063/1.1373737.

Green, D.M. \& Swets, J.M., 1966. Signal detection theory and Psychophysics; Wiley \& Sons, New York

Green, D.M. \& Swets, J.M., 1972. Signal detection theory and Psychophysics; Kreiger, Huntingdon, New York (Revised edition).

Guignard, P.A, \& Salehi, N., 1983. Validity of the Gaussian assumption in the analysis of ROC data obtained from scintigraphic-like image; Phys Med Biol. 28, 1409 - 1417.

Gundogdu, O., Nirgianaki, E., E. Che Ismail, Jenneson, P. M. and Bradley, D. A., 2007. Applied Radiation and Isotopes 65, 1337.

Gylin, K.M., \& Schwaninger, A. Drury, C.G., Redford, J., Lin, L. \& Batta R., 2008. Screening enhancements: why don't they enhance performance?; Proceedings of the Human Factors \& Ergonomics Society $52^{\text {nd }}$ Annual Meeting; Sept $22^{\text {nd }}-26^{\text {th }} 2008$, as cited in Wales et al, 2009

Harding, G. and Kosanetzky, J., 1989. Scattered X-ray beam nondestructive testing, Nuclear Instruments and Methods in Physics Research A280, 517-528

Harding, G., Jordan, B., and Kosanetzky, J., 1991. A new fluorescent x-ray source for photon scattering investigations. Phys. Med. Biol., 36, 1573-1583.

Harding, G., Delfs, J., 2008. Liquids Identification by x-ray diffraction, Proc. SPIE 6707, pp. 67070T, 2007a.doi:10.1117/12.740290

Harding, G., 2004. X-ray scatter tomography for explosives detection, Radiation Physics and Chemistry 71, 869-881.

Harding, G., Harding, A., 2007. Counter-terrorist Detection Techniques of Explosives, X-ray diffraction imaging, pp. 119-235, Elsevier, London.

Harding, G., 2006. Effective density and atomic number derived from x-ray diffraction profiles, Proc. SPIE 6319, pp. 631910.

Harding, G., 2008. Potential of x-ray diffraction for detecting special nuclear materials (SNMs), Proc. SPIE 7080, 70800K; doi:10.1117/12.800760. 
Herrmann, C.; Steadman, R.; Mulhens, O; (2010) ChromAIX: Fast energy resolved photon-counting readout electronics for future human Computed Tomography; Conference Proceedings of the IEEE Nuclear Science Symposium Conference Record (NSS/MIC), pp 1996 - 1999

Höfer, F. \& Schwaninger, A. Reliable and valid measures of threat detection performance in X-ray screening; IEEE ICCST Proceedings, 2004, Vol. 38, pp $303-308$.

Hubert Chen, C.M., Cook, W.R., Harrison, F.A., :in, J.Y.Y., 2004. Characterization of a large-format, fine pitch CdZnTe pixel detector for the HEFT balloon-borne experiment. IEEE Trans. Nucl. Sci. 51, 2472-2477.

Hukins, D. W. L., 1981. X-Ray Diffraction by Disordered and Ordered Systems, Pergamon, Oxford.

Johns, P.C., Yaffe, M.J., 1982. Scattered radiation in fan beam imaging systems. Med. Phys 9, 231-239.

Johns, P.C., Yaffe, M.J., 1983. Coherent Scatter in Diagnostic radiology. Med. Phys 10, 4050.

Kowase, K.; Ogawa, K., 2006. Photon Counting X-ray CT System with a Semiconductor Detector; IEEE Nuclear Science Symposium Conference Record, 3119 - 3123.

Kelcz, F., Joseph, P.M., Hilal, S.K., 1979. Noise considerations in dual energy CT scanning. Med Phys. 6, 418-425.

Knoll, G.F., 2000. Radiation Detection \& Measurement, Wiley, New York.

Lehmann, L.A., Alvarez, R.E., Macovski, A., et al. 1981. Generalized image combinations in dual $\mathrm{kVp}$ digital radiography. Med Phys. 8, 659-667.

Lewis, R.A. 2004. Medical phase contrast X-ray imaging: current status and future prospects. Phys. Med. Biol. 49, 3573-3583.

Liu, X, \& Gale, A., 2007. Searching for possible threat items to safe air travel: human error training; Proceedings of the $7^{\text {th }}$ International Conference on Engineering Psychology and Cognitive Ergonomics, Springer Verlag; ISBN 978-3-540-73330-0

Liu, X, \& Gale, A., 2011. What is the difference between naïve people and airport screeners?; Engineering Psychology and Cognitive Ergonomics; Lecture Notes in Computer Science 2011; Springer Verlag; Vol 6781; pp 424 - 431 
Liu, X, Gale, A. \& Song, T., 2007. Detection of Terrorist Threats in Air Passenger Luggage: Expertise Development; $41^{\text {st }}$ Annual IEEE International Carnahan Conference on Security Technology, pp 301- 306.

Markarian, G.Rainer Koelle R, \& Tarter, A, 2011. Aviation Security Engineering: A Holistic Approach (Artech House Intelligence and Information Operations); ISBN-10: 1608070727

Martz H. E. and Crawford C. R., 2011. Explosive Detection in Aviation Applications Using CT, 11th International Meeting on Fully Three-Dimensional Image Reconstruction in Radiology and Nuclear Medicine. Potsdam, Germany; July 11, 2011 through July 15, 2011. LLNL-CONF-471518;

Martz, H.E., Logan, C.M., Schneberk, D.J., Shull, P.J., 2010. X-Ray Imaging: Fundamentals, Industrial Techniques, and Applications, CRC Publishers; $1^{\text {st. }}$. edition

Matsuo, S., Katafuchi, T., Tohyama, K., Morishita, J., Yamada, K. and Fujita, H. 2005. Evaluation of edge effect due to phase contrast imaging for mammography Med. Phys. 32, 2690-2697.

Medwow, 2011. http://used-medicalequipmentblog.blogspot.com/2011/08/function-of-x-raytubes.html

Neiderman, E.C. \& Fobes, J.L. 2009. Operational test and evaluation of human factors interventions for airport security screeners; Human Factors \& Ergonomics Society Annual Meeting Proceedings, Test \& Evaluation, 4, 1094 - 1097.

McCarley, J.S., 2009. Response criterion placement modulates the benefits of graded alerting systems in a simulated baggage screening task; Human Factors \& Ergonomics Society Annual Meeting Proceedings, Vol 53, No. 17, pp 1106 - 1105(5)

Michel, S, Mendes, M., Schwaninger, A,. 2010. Can the difficulty level reached in computerbased training predict the results in x-ray image interpretation tasks?; 2010 International IEEE Carnahan Conference on Security Technology; 5-8IOct 2010, pp 146 - 15

Olivo, A., Ignatyev, K., Munro, P. R. T. and Speller, R. D., Non-interferometric phasecontrast images obtained with incoherent x-ray sources. Applied Optics, 50, 1765-1769.

Oster, C.V. and Strong, S.S., 2008. A review of Transportation Security Administration funding 2001 - 2007; J Transp Secur 1, 37 - 43. 
Pangaud, P., Basolo, S., Boudet, N., Berar, J-F, Chantepie, B., Delpierre, P., Dinkespile, B., Hustach, S., Menouni, M., Morel, C., 2006. XPAD3: A new photon counting chip for X-Ray CT-scanner. Nuclear Instruments and Methods in Physics Research Section A, 571, 321-324.

Poole, R.W., 2008. 'Toward Risk-Based Aviation Security Policy'; Joint Transport Research Centre; Discussion Paper 2002-23; Available at:

http://www.internationaltransportforum.org/jtrc/discussionpapers/DP200823.pdf

Ponchut, C, Visschers J L, Fornaini A, Graafsma H, Maiorino, M, Mettivier G, \& Calvet D; (2002) Evaluation of a photon-counting hybrid pixel detector array with a synchrotron X-ray source', Nuclear Instruments and Methods in Physics Research Section A, 484, 396406

Přibil J., Zat'ko, B., Frollo, I., Dubecký, F., Ščepko, P. and Mudroň, J., 2009. Quantum Imaging X-ray CT Systems Based on GaAs Radiation Detectors Using Perspective Imaging Reconstruction Techniques; Measurement Science Review, 9, 27-32.

Rebuffel, V., Rinkel, J.,, Tabary, J., Verger, L., 2011. New Perspectives of X-ray Techniques for Explosive Detection Based on CdTe/CdZnTe Spectrometric Detectors; International Symposium on Digital Industrial Radiology and Computed Tomography - We.2; pp 1-8.

Rowlands, J., Kasap, S., 1997. Amorphous semiconductors usher in digital x-ray imaging, Physics Today 24, 30.

Sample, K.S., Taylor, D.K. and Rao, E., 2004. High Tech aviation security program in Africa - A model for technology transfer; Security Technology, 38th Annual 2004 International Carnahan Conference pp 270-277.

Schwaninger, A, Michel, S, \& Bolfing, A., 2007. A statistical approach for image difficulty estimation in x-ray screening using image measurements; ACM International Conference Proceedings Series 253, pp 123 - 130, as cited in Wales et al, 2009.

Schwaninger, A., Hardmeier, D. \& Höfer, F., 2005. Aviation security screeners visual abilities and visual knowledge measurement; IEEE A\&E Systems Magazine; June 2005; pp $29-35$.

Schwaninger, A., Hardmeier, D. \& Höfer, F., 2004. Measuring visual abilities and visual knowledge of aviation security screeners; $38^{\text {th }}$ Annual IEEE International Carnahan Conference on Security Technology, pp 258- 264. 
Schweitzer, Y, Institute of Counter Terrorism, 2002. The Case of the "Shoe Bomber"

Lessons in counter-terrorism-this time at no cost; 2002; Available at

http://212.150.54.123/articles/articledet.cfm?articleid=423

Segan, S., 2011. Flying 10 Years After 9-11: The Good, the Bad, and the Ugly; http://www.frommers.com/articles/7431.html\#ixzz1b8s8UkJH

Seidenstat, P. and Splane, F. X., 2009. Protecting Airline Passengers in the Age of Terrorism; (Praeger Security International), ISBN-10: 0313354537

Singh, S. and Sing, M., 2003. Explosives Detection Systems (EDS) for Aviation Security: A Review. Signal Processing, 83.

TSA, 2009, Electronic Baggage Screening Program: Program Specific Recovery Act Plan, May 15, 2009. Available online at:

http://www.dhs.gov/xlibrary/assets/recovery/TSA_EBSP_Recovery_Act_Plan_Final_200905-15.pdf

Wales, A, Halbherr, T, Schwaninger, A., 2009. Using speed measure to predict performance in x-ray luggage screening tasks; $43^{\text {rd }}$ Annual Carnahan Conference on Security Technology; 5-6lOct 2009, $212-215$.

Wang, A. S., Harrison, D., Lobastov, V., and Tkaczyk, J. E., 2011. Pulse pileup statistics for energy discriminating photon counting x-ray detectors; Medical Physics, 38, 4285 - 4275.

Weitkamp, T., Diaz, A., David, C., Pfeiffer, F., Stampanoni, M., Cloetens, P., and Ziegler, E., 2005. X-ray phase imaging with a grating interferometer. Optics Express, 12, 6296.

Wilkins, S. W., Gureyev, T. E., Gao, D., Pogany, A., and Stevenson, A. W., 1996. Phasecontrast imaging using polychromatic hard X-rays, Nature, 384, 335.

Yadav, J.S., Savitri, S., Malkar, J.P., 2005. Near room temperature $X$ and $\gamma$-ray spectroscopic detectors for future space experiments. Nucl. Instr. Meth. Phys. Res. A552, 399-408.

Ying Z., Naidu R., Guilbert K., Schafer D., and Crawford C. R., 2007. Dual Energy Volumetric X-ray Tomographic Sensor for Luggage Screening. IEEE Sensors Applications Symposium, San Diego, California USA, 6-8 February 2007. 